\title{
Eco-evolutionary partitioning metrics: a practical guide for biologists
}

\author{
Lynn Govaert ${ }^{1,2,3}$ \\ ${ }^{1}$ Laboratory of Aquatic Ecology, Evolution and Conservation, University of Leuven, \\ Ch. Deberiotstraat 32, B-3000 Leuven, Belgium. \\ ${ }^{2}$ Department of Evolutionary Biology and Environmental Studies, \\ University of Zurich, Winterthurerstrasse 190, CH-8057 Zürich, Switzerland. \\ ${ }^{3}$ Eawag: Swiss Federal Institute of Aquatic Science and Technology, Department of Aquatic Ecology, \\ Überlandstrasse 133, CH-8600 Dübendorf, Switzerland. \\ Emails: Lynn.Govaert@kuleuven.be, Lynn.Govaert@eawag.ch

\begin{abstract}
It is well-known that ecological and evolutionary processes can occur on similar time scales resulting in eco-evolutionary dynamics. One of the main questions in eco-evolutionary dynamics involves the assessment of the relative contribution of evolution, ecology and their interaction in the ecoevolutionary change under study. This has led to the development of several methods aimed to quantify the contributions of ecology and evolution to observed trait change, here referred to as eco-evolutionary partitioning metrics. This study provides an overview on currently-used partitioning metrics with a focus on methods that can quantify evolutionary and non-evolutionary contributions to population and community trait change. I highlight key differences between these metrics found in previous studies. Additionally, I also provide a detailed comparison between the 'Geber' method and the reaction norm approach. Next, I provide a guideline for researchers to assess which metrics are best suited for their data, give an overview on the type of data needed for these metrics, and how this data can be collected with a focus on community data.
\end{abstract}

Key words. Price equation, reaction norms, eco-evolutionary partitioning metrics, community ecology, trait change.

Govaert L. (2018). Eco-evolutionary partitioning metrics: a practical fuide for biologists. Belgian Journal of Zoology 148 (2): 167-202. https://doi.org/10.26496/bjz.2018.25

\section{Introduction}

Eco-evolutionary dynamics can be seen as a sub-discipline of evolutionary ecology (SHEFFERSON \& SALGUERO-GÓMEZ 2015), one that considers the reciprocal interactions between (rapid) evolutionary change and ecological processes (FUSSMANN et al. 2007; SCHOENER 2011; HENDRY 2017). The use of the term 'dynamics' suggests that the reciprocal interactions between ecology and evolution are characterised by a constant change. The classical view of eco-evolutionary dynamics is that it consists of two pathways: an eco-to-evo and an evo-to-eco pathway (FUSSMANN et al. 2007; SCHOENER 2011; HENDRY 2017). The eco-to-evo pathway has been widely recognised and emphasises the fact that ecological processes impose selection pressures on individuals and hence can influence species evolutionary trajectories. For example, for the Darwin finches on the Galápagos Islands, it has been 
found that the changes in seed availability (eco) result in different selection regimes on the beak sizes (evo) of the finches (HENDRY 2017). The evo-to-eco pathway has been less well recognised, and is mainly inspired by the awareness that evolutionary processes can be rapid, occurring on similar time scales as ecological processes and thus influence these ecological properties. For example, the evolution in beak sizes (evo) of a specific Darwin finch population can impact its population growth (eco; HAIRSTON et al. 2005), but also the seed community structure (eco; POST \& PALKOVACS 2009; HENDRY 2017).

The emerging field of eco-evolutionary dynamics gained a lot of attention during the last few decades (ShefFerson \& SAlguero-Gómez 2015; Hendry 2017; Fig. 1). The increase in studies on ecoevolutionary dynamics mainly involve empirical work on animals and microbes, and theoretical and review papers exploring the potential for eco-evolutionary feedbacks (SHEFFERSON \& SALGUEROGóMEZ 2015). One of the original attempts to understand the interactions between ecology and evolution was David PimenTEL's $(1961,1968)$ groundbreaking work on 'genetic feedback', a mechanism for population regulation between predator-prey or host-parasite interactions. In this feedback, frequencies of different genotypes in a host population are expected to shift as the overall density of the host population or an interacting (predator, parasite) population changes. This shift in population genetic composition then feeds back to cause a change in the density of the predator or parasite population, which again shifts the selection pressure on the host population and so on.

The genetic feedback mechanism of PimenTEL $(1961,1968)$, a few years later also mathematically modelled by LEVIN (1972), was one of the first studies that both developed a model on how interactions between ecology and evolution might work and at the same time evaluated that model empirically (REZNICK 2013). Since then, several studies have documented the consequences of rapid evolutionary changes on ecological properties and processes, including changes in population dynamics (YOSHIDA et al. 2003, 2007; TURCOTTE et al. 2011; BECKS et al. 2012), community structure (POST \& PALKOVACS 2008), and nutrient cycles (BASSAR et al. 2012).

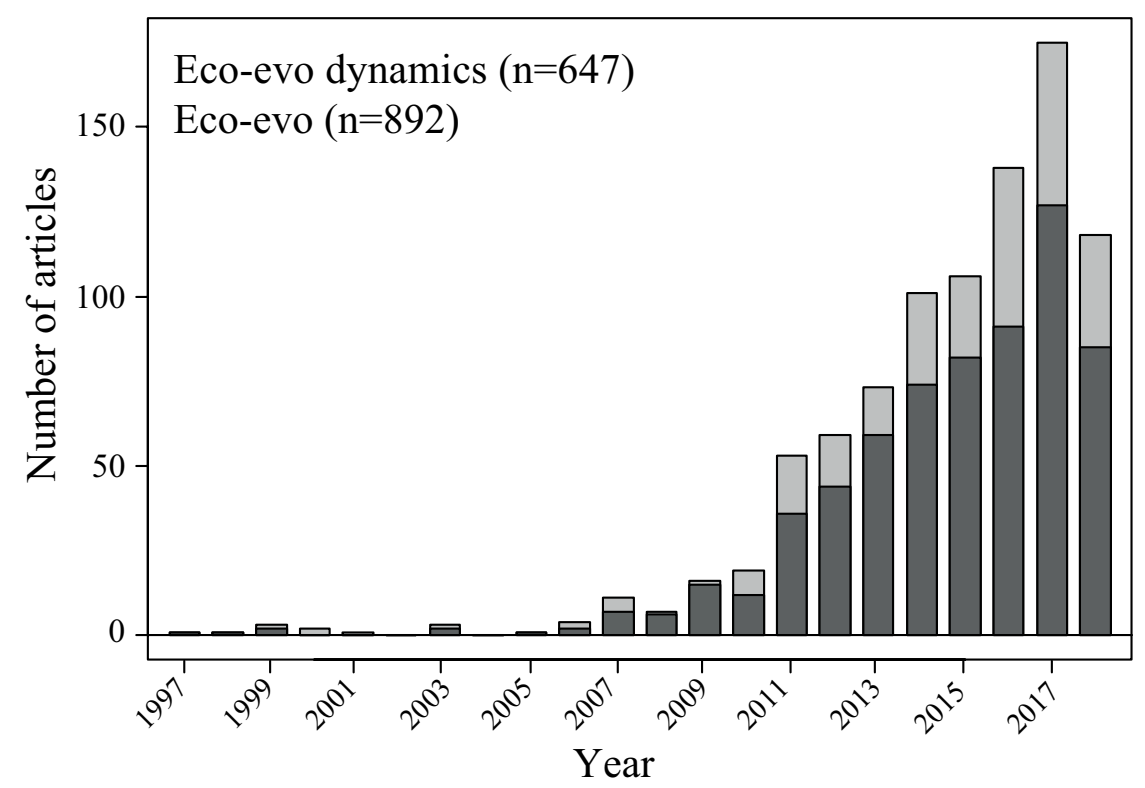

Fig. 1 - Number of scientific papers published since 1996 on eco-evolutionary dynamics at September 2018. The search terms [eco-evo* dynamics] (dark grey bars) and [eco-evo*] (light grey bars) were used in Web of Science database. (modified from SHEFFERSON \& SALGUERO-GóMEZ 2015). 


\section{The gear of eco-evolutionary dynamics}

Phenotypes can be considered the gear of eco-evolutionary dynamics because selection acts directly on phenotypes regardless of their genetic basis and because organisms will have ecological effects that are driven by their phenotypes rather than their genotypes (HENDRY 2017; Fig. 2). Therefore, genotypes will be affected by selection rather indirectly through their link with phenotypes and they will have ecological effects indirectly through their influence on phenotypes (HENDRY 2017). These two reasons clarify why studies on eco-evolutionary dynamics focus rather on phenotypes than on genotypes. The focus on phenotypic rather than genotypic (evolutionary) change in eco-evolutionary dynamics brings the issue that other, non-genetic, factors such as phenotypic plasticity might also contribute to the phenotypic change observed (Fig. 2).

Phenotypic plasticity is the ability of a single genotype to express different phenotypes depending on the environmental context given (DEWITT et al. 1998) and may shift the observed phenotypic trait value

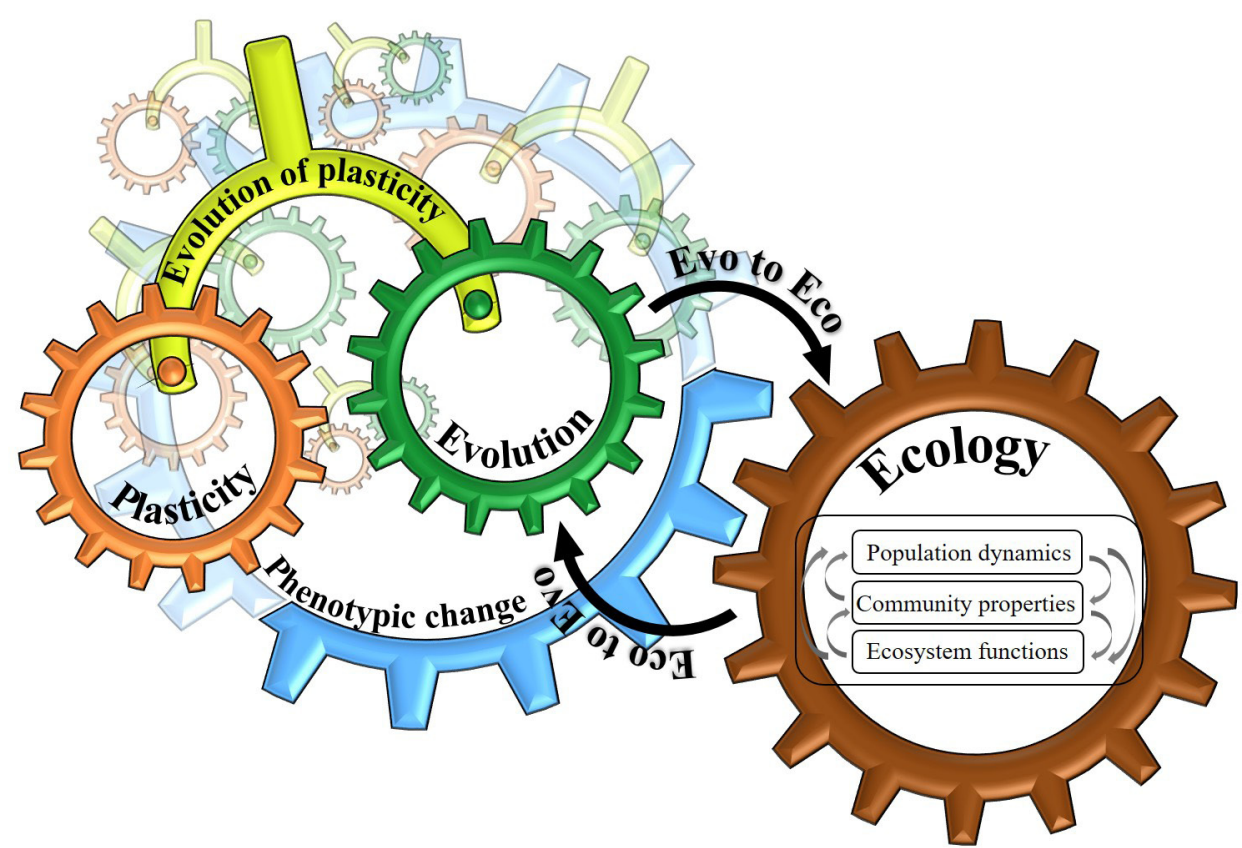

Fig. 2 - Graphical illustration of eco-evolutionary dynamics in a multi-species context. The blue gear represents the community phenotypic trait change. Phenotypes can be considered to be the gear of eco-evolutionary dynamics as selection acts directly on phenotypes rather than genotypes and because organisms have ecological effects which are driven by their phenotypes (HENDRY 2017). Therefore phenotypic trait change plays a crucial role in linking ecological (depicted with the brown gear) and evolutionary (depicted with the green gear) changes to each other. However, a species phenotypic trait also has a non-evolutionary part (i.e., phenotypic plasticity; depicted with the orange gear), and changes in species relative abundances may also alter the community phenotypic trait (the different green and orange linked gear wheels). Hence, in a community context, a community phenotypic trait may change because species evolve, respond plastically, and species change in relative abundances. In order to have an accurate quantification of how important evolution is to phenotypic trait change in eco-evolutionary dynamics, methods are needed that can accurately separate evolutionary from non-evolutionary (such as plasticity and species sorting) effects. Note that the different sizes of the green and orange linked gear wheels represent a species contribution to community phenotypic trait change. This may reflect proportional species abundances, but also species interaction strengths. 
of a population. Both rapid evolution and plasticity might provide adaptive changes in a population, increasing the fitness of the individuals of that population. However, most eco-evolutionary studies have looked at phenotypic effects on ecology without separating their genetic and plastic basis (HENDRY 2013). For example, HARMON et al. (2009), found that the benthic and limnetic form of the threespine stickleback has different effects on its prey community structure. Other studies have also quantified the effects of different fish ecotypes on community variables (e.g., POST \& PALKOVACS 2009; DeS ROCHES et al. 2013), and these studies have used only wild-caught fish, for which genetic and plastic effects cannot be separated (HENDRY 2013). There are, however, a set of tools available that can be used to disentangle genetic change from plasticity effects (MERILÄ \& HENDRY 2014): quantitative genetic animal models, transplant and common-garden experiments, and experimental manipulations (ELLNER et al. 2011). First, quantitative genetic animal models fit linear mixed-effects models to individual-level data. They can determine to which extent a temporal phenotypic change has a quantitative genetic basis (HENDERSON 1950) assuming that the trait is influenced by many genes with small effects (ROFF 2007). In these types of models, plasticity is then inferred as the proportion of the phenotypic trend that cannot be ascribed to genetic change. For example, RÉALE et al. (2003) found that plasticity accounted for $62 \%$ of the change in parturition date in a red squirrel population using an animal model. A disadvantage of this method is the need for detailed pedigree data that is often only available in long-term studies of individually marked populations (e.g., RÉAlE et al. 2003; CHARMENTIER et al. 2008; PIGÉON et al. 2017), which for some organisms might be difficult to collect. Second, transplant and commongarden experiments are often used to detect signals of local adaptation (KAWECKI \& EBERT 2004). In a transplant experiment, individuals originating from different locations are transplanted among all locations. When this is impossible, an alternative approach is to create a controlled environment or a range of environmental conditions in the laboratory or in the field, and expose different genotypes to these conditions. This experimental set-up is referred to as a common-garden experiment. Both approaches allow the construction of reaction norms, which can then be used to separate genetic and environmental effects of the phenotype (VIA et al. 1995; KAWECKI \& EBERT 2004; WILLIAMS et al. 2008). Lastly, experimental manipulations such as experimental evolution, in which experimental populations exposed to different environmental conditions are established, can be used to examine evolutionary or plasticity responses (MERILÄ \& HENDRY 2014). For example, VAN DOORSLAER et al. (2007) showed rapid microevolutionary responses in survival and performance of Simocephalus vetulus populations after 1 year of exposure to different temperature treatments mimicking different global warming scenarios using outdoor mesocosms.

To date, most eco-evolutionary studies have focused on single traits of single species, while it is known that communities can also be structured by ecological and evolutionary processes (COLLINS \& GARDNER 2009; BARRACLOUGH 2015), not only in time but also in space (VIA \& LANDE 1985; KAWECKI \& EBERT 2004; FOX \& HARDER 2015), and that selection can act on multiple traits at the same time (LANDE \& ARNOLD 1983) resulting in biased outcomes expected from single trait studies (VIA \& LANDE 1985; VIA \& HAWTHORNE 2005). Having tools available to not only disentangle plasticity from evolutionary change, but also from ecological processes at the community level (e.g., changes in the relative abundances of species) will aid the field of eco-evolutionary dynamics to look at more complex systems shaped by interacting ecological and evolutionary processes. Eco-evolutionary partitioning metrics are an example of such a tool that allows the quantification of ecological and evolutionary contributions to population and community trait change. The data used for these types of metrics often make use of the previously described techniques of quantitative genetic models, common garden or transplant experiments and experimental evolution.

\section{Eco-evolutionary partitioning metrics}

Partitioning metrics have been developed with two goals: quantifying the contribution of genetic and non-genetic components to (1) trait change (e.g., the reaction norm approach; STOKS et al. 2016) and 
(2) an ecological or community variable (e.g., the 'Geber method'; HAIRSTON et al. 2005; ELLNER et al. 2011). An overview of key studies developing or using eco-evolutionary partitioning metrics, related to both goals, is given in Fig. 3. While some of these methods were originally developed outside the field of eco-evolutionary dynamics (e.g., HENDERSON 1950; FOX 2006; LAJOIE \& VELLEND 2015), small modifications could make them relevant for studying eco-evolutionary trait change (e.g., BRANS et al. 2017). Next, I give an overview on current existing partitioning metrics aimed at quantifying contributions of ecology and evolution to population and community trait change.

\section{Population level}

\section{The Price equation}

Partitioning metrics designed to determine the role of evolution and ecology to observed trait change often make use of the Price equation (PRICE 1970, 1972; detailed derivation in Supplementary file A). The Price equation has been suggested to be the most fundamental theorem of evolution, because of its simplicity, and broad scope (QUELLER 2017). QUELLER (2017) showed that the Price equation can be used to derive Fisher's average-excess equation (FISHER 1930, 1941), Robertson's secondary theorem of natural selection (ROBERTSON 1966, 1968), the breeder's equation (LUSH 1947) and Fisher's fundamental

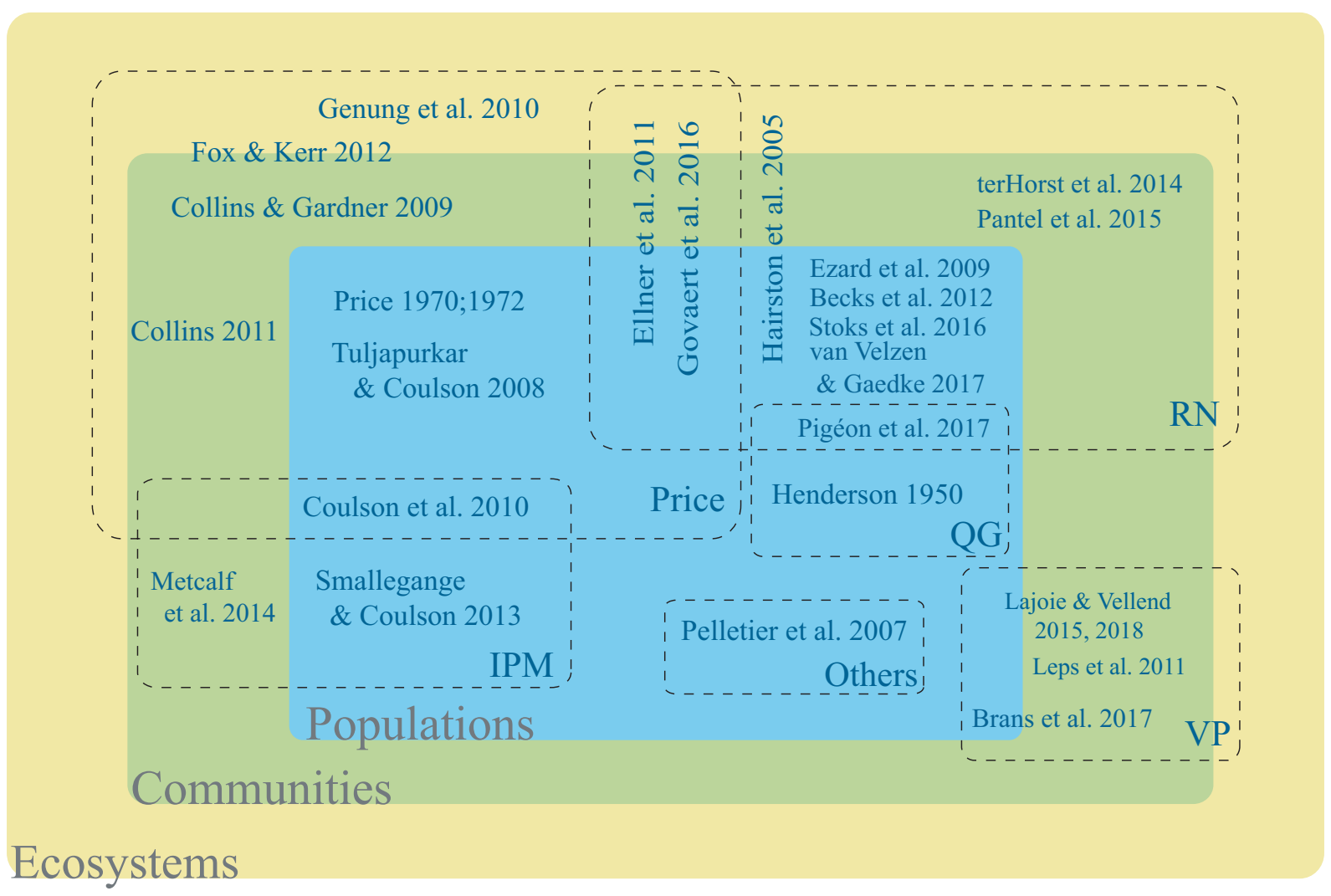

Fig. 3 - Overview on few key studies using eco-evolutionary partitioning metrics that are based on the Price equation (Price), reaction norms (RN), integral projection modeling (IPM), quantitative genetics (QG), variation partitioning methods (VP) and others (Others) that can be used to separate intraspecific, interspecific, evolutionary and non-evolutionary contributions to population (blue), community (green) and ecosystem (yellow) change. Studies that combine different methods are given in intersecting regions. Note that the reaction norm approach and the (discrete) 'Geber' method are both grouped under metrics using reaction norms. While both methods can use the same type of data, they should not be conflated entirely as they have crucial differences in the interpretation of the components (see main text). 
theorem (FISHER 1930). Although the Price equation by itself is very simple, it can be easily extended to incorporate several complexities, such as uncertainty (GRAFEN 2000; RICE 2008), migration (KERR \& Godfrey-SMith 2009; Rice \& PAPAdOPOUlos 2009), or class (GRAFEN 2015) and age structure (COULSON \& TUlJAPURKAR 2008). The Price equation is indeed a very attractive method, and has proven its usefulness in many fields, such as evolutionary biology (detailed in QUELLER 2017), ecology (FOX 2006; FOX \& KERR 2012) and epidemiology (DAY \& GANDON 2006). It is therefore no surprise that the Price equation also found its way into eco-evolutionary dynamics (COLLINS \& GARDNER 2009; Ellner et al. 2011; GOVAERT et al. 2016). In GOVAERT et al. (2016), the Price equation was used to quantify contributions of lineage sorting (i.e., changes in the relative abundances of the different genetic lineages) and the trait change within lineages to observed temporal population trait change of an asexually reproducing population consisting of $N$ different genetic lineages, uniquely indexed as $j \in\{1, \ldots, N\}$, i.e.,

$$
\Delta \bar{z}=\sum_{j=1}^{N} z_{2}^{j}\left(q_{2}^{j}-q_{1}^{j}\right)+\sum_{j=1}^{N} q_{1}^{j}\left(z_{2}^{j}-z_{1}^{j}\right)
$$

In eqn $1, z_{1}^{j}$ (resp. $z_{2}^{j}$ ) denotes the average trait value of genetic lineage $j$ at time point $t_{1}$ (resp. $t_{2}$ ), and $q_{1}^{j}$ (resp. $q_{2}^{j}$ ) denotes the relative abundance of genetic lineage $j$ at time point $t_{1}$ (resp. $t_{2}$ ). The first term on the right-hand side of eqn 1 captures lineage sorting and the second term the trait change within lineages. In this version of the Price equation the categorisation occurs via the distinct genetic lineages, and not on a one-to-one parent-offspring relationship. This means that there might be many generations between the two time points of trait change.

\section{Integral projection modelling}

While not a classical tool to quantify contributions of evolution and ecology to trait change, integral projection models (IPMs) have been used to answer eco-evolutionary questions (e.g., MetCALF et al. 2008; Smallegange \& Coulson 2013; Traill et al. 2014). An IPM is a matrix population model that tracks the dynamics of a continuous trait (e.g., body size) in discrete time (EASTERLING et al. 2000; COULSON 2012). It describes the state of the population as a distribution, linking the continuous trait to four vital rate functions: (i) survival from time $t$ to $t+1$, (ii) trait value of the survived individuals at time $t+1$, (iii) the number of offspring produced from time $t$ to $t+1$ given the trait value at time $t$, and (iv) the trait values of the offspring at time $t+1$ (COULSON 2012). These four functions form the kernel of the IPM and allow the description of the population trait change through time (EASTERLING et al. 2000; COULSON 2012). Age-structured IPMs have been combined with an extended version of the Price equation, the age-structured Price equation (COULSON \& TULJAPURKAR 2008), to allow a specific decomposition of the trait change given by the IPM into contributions of genetic, non-genetic and demographic processes (COULSON et al. 2010). For example, a study by OzGUL et al. (2010) applied the age-structured Price equation to a fitted IPM of a Soay sheep population at St Kilda and found that most of the change in body mass was due to ecological rather than evolutionary processes. Another way to assess the effects of these processes on the population mean trait involves the use of sensitivity analysis (e.g., COULSON et al. 2011; TRAill et al. 2014). This approach, however, does not partition the mean trait change into contributions of ecology and evolution, but rather assesses how small perturbations of specific processes influence the population mean trait (COULSON et al. 2011). A disadvantage of IPMs is the need for detailed individual-level data along multiple time points.

\section{The partitioning method of HAIRSTON et al. (2005) and ELLNER et al. (2011)}

One of the first developments to assess interactions between ecology and evolution, inspired by Pimentel's approach, was introduced in 2005 by N. Hairston Jr. and colleagues. Their method, in some studies referred to as the 'Geber' method (e.g., BECKS et al. 2012; PIGÉON et al. 2017, VAN BENTHEM et al. 2017; VAN VELZEN \& GAEDKE 2017), uses a technique of variance analysis to partition variation in an ecological response variable indicated by $X$ (e.g., population growth rate) into evolutionary (via a 
phenotypic trait $z$ ) and ecological (via ecological factor $e$ ) contributions, i.e., $X=X(z, e)$. The main setup of this method is the link of the ecological response variable with a phenotypic trait and ecological factor. With continuous data, they proposed to use the chain rule to disentangle change in $X$ due to evolutionary changes in $z$ and ecological changes in $e$ (HAIRSTON et al. 2005). When having discrete data, however, they proposed using regression analysis to estimate the independent main effects of evolutionary and ecological changes. Specifically, formulae for ecological and evolutionary effects are obtained by solving least-squares normal equations for the model coefficients of a regression model without interaction component (HAIRSTON et al. 2005; ELLNER et al. 2011), resulting in the following formulae for the main effect of ecology and evolution to change in an ecological response variable $X$ :

$$
\begin{gathered}
\text { Ecology: } \frac{1}{2}\left(\left[X_{12}-X_{11}\right]+\left[X_{22}-X_{21}\right]\right) \\
\text { Evolution: } \frac{1}{2}\left(\left[X_{21}-X_{11}\right]+\left[X_{22}-X_{12}\right]\right),
\end{gathered}
$$

where $X_{k l}$ represents the value of the ecological response variable $X$ at genetic state $k$ and ecological state $l$, i.e., $X_{k l}=X\left(z_{k}, e_{1}\right)$. In this model $X$ is implemented as the response variable in function of two indicator variables indicating whether the ecological (i.e., environmental condition) or genetic (genetic make-up of the population) states refer to time point 1 or 2. HAIRSTON et al. (2005) used this method to demonstrate that in some instances evolutionary effects can be substantially larger than ecological effects. For example, in the medium ground finch Geospiza fortis population on Daphne Major Island, evolutionary contributions (via beak shape and body size) to population growth rate were shown to exceed ecological contributions (via seed density and fraction of large seeds) by a factor of 2.2 (HAIRSTON et al. 2005). In a second example, they showed that in a predator-prey simulation model of ABRAMS \& MATSUDA (1997), evolutionary effects (via prey vulnerability) to predator growth rate was $63 \%$ of the ecological contribution (via prey abundance). In a last example, for the copepod Onychodiaptomus sanguineus, an evolutionary contribution (via life history: switch-to-diapause date) to average percapita production of diapausing eggs in a given year was found to equal one-fourth of the ecological contribution (via fish predation). While this contribution was less compared to the other two examples, it nevertheless was not negligible.

In a study on five ungulate populations, EZARD et al. (2009) used the partitioning method of HAIRSTON et al. (2005) to disentangle change in annual population growth rate of each ungulate population into evolutionary (via birth weight) and ecological (via environmental variation such as June rainfall, vegetation index or Pacific Decadal Oscillation) contributions. While they found that both contributions were similar and therefore both processes could not be neglected, they raised an important issue with the original formulation of the method, which was that using a phenotypic trait as 'evolutionary variable' does not necessarily reflect evolutionary change. Observed changes in a phenotypic trait through time might also result from, for example, phenotypic plasticity (PIGLIUCCI 2001; NUSSEY et al. 2005a, 2005b) or changes in the age structure of the population (COULSON \& TULJAPURKAR 2008). The original formulation of the method by HAIRSTON et al. (2005) implies that the phenotypic trait used is perfectly heritable. While this is very unlikely, in some studies this has been the case (e.g., BECKS et al. 2012). In 2011, S.P. Ellner and colleagues improved the method of HAIRSTON et al. (2005) by using a continuous version of the Price equation (PAGE \& NOWAK 2002) to account for the nonheritable part in the phenotypic trait when having continuous data. Applied to discrete data, however, the method in HAIRSTON et al. (2005) was modified by allowing the phenotypic trait $z$ to also depend on the environment by using reaction norms, i.e., $X_{k l}=X\left(z_{k p} e_{l}\right)$ as opposed to $X_{k l}=X\left(z_{k} e_{l}\right)$ (also referred to as the 'Price-Geber' method; detailed in ElLnER et al. 2011).

While the method of HAIRSTON et al. (2005) and ELLNER et al. (2011) is very attractive, it still has limited implementation in the field of eco-evolutionary dynamics. Besides the study of EZARD et al. (2009), described earlier, five additional studies have used the 'Geber' or 'Price-Geber' method to quantify ecological and evolutionary contributions in their study system. For example, BECKS et al. 
(2012) showed that predator population growth was affected more by prey evolution (via clumping size) than by changes in prey abundance in predator-prey (rotifer-alga) microcosms experiments. In 2014, C.P. terHorst and colleagues reported the ecological effect of drought and the response of plant evolution to drought on soil microbial communities, and showed that the relative importance of ecological and evolutionary contributions on microbial communities were similar. In a later study, PANTEL et al. (2015), used an extension of the method of ELLNER et al. (2011) to incorporate two ecological factors that describe either the presence or absence of fish predation and macrophytes in their mesocosm experiments involving zooplankton communities. Using this extended version they showed that the impact of Daphnia magna adaptation to fish or macrophytes on the zooplankton community composition was similar to the effect of adding fish or macrophytes to mesocosm experiments. Similarly, PIGÉON et al. (2017) also used an extended version of the method of ELLNER et al. (2011) in combination with a quantitative genetic model to quantify the effects of heritable and non-heritable changes in body mass distribution versus age structure, population density and climate effects on survival, recruitment and population growth in the wild bighorn sheep Ovis canadensis. They showed that the importance of these effects changes substantially over time, and that overall, the changes in body mass distribution occurred mainly through non-heritable trait changes, which had similar effects as changes in age structure or density on population growth rate. Lastly, a study by VAN VELZEN \& GAEDKE (2017) used the continuous version of this method to calculate effects of prey and predator density and of trait defense and offense on prey and predator population growth in a predator-prey eco-evolutionary simulation to determine whether the prey and predator reinforce each other or not.

The five previously mentioned studies have used the same method to quantify ecological and evolutionary contributions to an ecological response variable. However, two of them did not incorporate a direct link between the ecological response variable $X$ and a phenotypic trait $z$. For example, both TERHORST et al. (2014) and PANTEL et al. (2015) experimentally measured the different states of their ecological response variable under study. These measurements were then directly used to assess how evolutionary (i.e., changes in genetic states) and ecological (i.e., changes in environmental states) effects shift the ecological response variable. On the one hand this simplifies the use of eqn 2 . On the other hand, one needs to experimentally evaluate all possible combinations for $X$, and this can be empirically challenging. Hence, the metric of ELLNER et al. (2011) can be used to evaluate the contribution of ecology and evolution to ecological change with or without the link to a phenotypic trait. For the former, combinations of $X$ can then be estimated by using a regression model with $X$ as a response variable, and $z$ and $k$ as predictor variables. For the latter, direct measurements of the ecological variable should be taken in order to use the formula given in eqn 2.

\section{The reaction norm approach}

A related method to the discrete reaction norm based method of ELLNER et al. (2011) is the reaction norm approach developed in STOKS et al. (2016) and GOVAERT et al. (2016). This method was originally developed to partition effects of (ancestral) plasticity, constitutive (i.e., mean trait) evolution and evolution of plasticity to temporal population trait change in a trait $z$ between two discrete time points corresponding to two distinct environmental conditions (e.g., low nutrient condition at the first time point, and high nutrient condition at the second time point). In cases where information on the population mean trait value at both time points in both conditions is known, $\Delta \bar{z}$ can be separated in the following components:

$$
\begin{aligned}
& \text { Plasticity : } z_{12}-z_{11}, \\
& \text { Const. evolution : } z_{21}-z_{11}, \\
& \text { Evo. of plast. : }\left[z_{22}-z_{21}\right]-\left[z_{12}-z_{11}\right] .
\end{aligned}
$$

In equation $3, z_{k l}$ refers to the average population trait value at time point $k$ in environmental condition l. The indices used here are similar to the ones used in the metric of ElLNER et al. (2011) in which the first index refers to the genetic state of the population corresponding to the time point and the second to the environmental state. Equation 3 has been used by STOKS et al. (2016) to quantify the effects 
of plasticity, constitutive evolution and evolution of plasticity to observed changes in 14 life history, morphological and behavioural traits of a Daphnia magna population undergoing shifts in fish predation pressure. This study used a resurrection ecology approach in which trait data on three discrete time points was collected, corresponding to two transition periods: no fish to high fish predation pressure (time period 1 to time period 2) and high fish to reduced fish predation pressure (time period 2 to time period 3). From each of these three time periods trait values of 12 clones were assessed in a control and fish kairomone condition, allowing the construction of reaction norms, and the use of the reaction norm approach. The main conclusions from this study were that the transition period from no fish to high fish predation pressure was mostly characterised by larger contributions of evolution of plasticity, while the transition period from high fish to reduced fish predation pressure was mostly characterised by larger contribution of constitutive evolution. For the first transition period, no general pattern among traits in which plasticity, constitutive evolution and evolution of plasticity worked in opposite or the same direction to the observed trait change was found. For the second transition period, however, plasticity always occurred in the same direction as constitutive evolution and in the opposite direction to evolution of plasticity. A similar conclusion as for the first transition period was obtained when the reaction norm approach was applied to three Polygonum cespitosum populations in New England, i.e., plasticity and the evolutionary components contributing to the observed trait change were found to combine in distinct ways for the same traits in different populations (GOVAERT et al. 2016). In a later study by FRONHOFER et al. (2017), the reaction norm approach has been extended for the use of continuous reaction norms.

\section{Community level}

The previously described methods use a phenotypic trait $z$ of a single species (i.e., a trait at the population level) either directly (Price equation, reaction norm approach) to quantify ecological and evolutionary contributions to the observed change in $z$ or indirectly as a link to an ecological response variable ('Geber' and 'Price-Geber' method) for which ecological and evolutionary contributions are calculated. However, in natural systems, species are often part of a larger set of multiple species comprising a community. In some cases it might be that the average community phenotype influences the ecological response variable of interest rather than the average population trait. Moreover, the phenotypic community trait may change due to plasticity responses and/or evolutionary changes of the individual species, but also via changes in the relative abundances of the species (further referred to as species sorting; BARRACLOUGH 2015; GOVAERT et al. 2016). Therefore, community trait change can be separated in ecological and evolutionary contributions and hence there is a need for partitioning metrics that can quantify these components. The Price equation and the reaction norm approach have been extended to allow for the assessment of ecological and evolutionary contributions to community trait change. In the case of the Price equation, a straightforward extension to communities is possible due to its recursive property (ARNOLD \& FRISTRUP 1982) and has been used in an eco-evolutionary context (GOVAERT et al. 2016). In the latter study, a community version of the reaction norm approach has been developed and has been shown to quantify effects of plasticity, constitutive evolution and evolution of plasticity, but also changes in the relative abundances of the species (species sorting), and interactions between species sorting and the evolutionary components (GOVAERT et al. 2016). Next, I discuss three other metrics that can be used to quantify evolutionary and ecological contributions at the community level (hence including changes in species abundances).

\section{The Price-based equation of COLLINS \& GaRDNER (2009)}

COLLINS \& GARDNER (2009) used a Price-based approach on a community of $s$ asexually reproducing species, where each species consists of distinct genetic lineages, to disentangle community trait change between two consecutive time points into species sorting, evolutionary and physiological change (e.g., mutation, physiological effects mediated through community composition, but see COLLINS \& GARDNER 2009), i.e., 


$$
\Delta \bar{z}=\sum_{i=1}^{s} z_{2}^{i}\left(q_{2}^{i}-q_{1}^{i}\right)+\sum_{i=1}^{s} \sum_{j=1}^{N_{i}} q_{1}^{i j} z_{2}^{i j}\left(\frac{q_{2}^{i j}}{q_{1}^{i j}}-\frac{q_{2}^{i}}{q_{1}^{i}}\right)+\sum_{i=1}^{s} \sum_{j=1}^{N_{i}} q_{1}^{i j}\left(z_{2}^{i j}-z_{1}^{i j}\right)
$$

In eqn $4, z_{1}^{i}$ and $z_{2}^{i}$ (resp. $q_{1}^{i}$ and $q_{2}^{i}$ ) represent the average trait value (resp. relative abundance) of species $i$ at time point $t_{1}$ and $t_{2}, z_{1}^{i j}$ and $z_{2}^{i j}$ (resp. $q_{1}^{i j}$ and $q_{2}^{i j}$ ) represent the average trait value (resp. relative abundance in the total community) of genetic lineage $j$ of species $i$ at time point $t_{l}$ and $t_{2}$. The first term on the right-hand side of eqn 4 captures the species sorting component, the second term captures the lineage sorting component and the last term captures the physiological component. COLLINS \& GARDNER (2009) describe physiological change to reflect shifts in individual trait values that can be ascribed to different processes, such as mutation, or a plasticity response mediated by a change in community composition. Using their equation, COLLINS \& GARDNER (2009) found roughly equal contributions of evolution and ecology (however in opposite direction) to the response of a phytoplankton community to chronic levels of diuron exposure. For a detailed explanation of the method I refer the reader to COLLINS \& GARDNER (2009).

\section{The Price-Reaction-Norm equation}

At both the population, and community level, GOVAERT et al. (2016) combined the Price equation and the reaction norm approach resulting in the Price-Reaction-Norm (PRN) equation. At the community level, this equation depends upon a community version of the Price equation using the recursive property of the Price equation (i.e., substituting a Price equation into a Price equation; PRICE 1972; HAMILTON 1975; ARNOLD \& FRISTRUP 1982) combined with the community version of the reaction norm approach (detailed calculations in GOVAERT et al. 2016). The Price-Reaction-Norm equation then separates observed mean community trait change $\Delta \bar{Z}$ into the following components:

$$
\begin{aligned}
\Delta \bar{z}= & \sum_{i=1}^{s} z_{12}^{i}\left(q_{2}^{i}-q_{1}^{i}\right)+\sum_{i=1}^{s}\left(q_{2}^{i}-q_{1}^{i}\right) \sum_{j=1}^{N_{i}} z_{22}^{i j}\left(\frac{q_{2}^{i j}}{q_{2}^{i}}-\frac{q_{1}^{i j}}{q_{1}^{i}}\right) \\
& +\sum_{i=1}^{s}\left(q_{2}^{i}-q_{1}^{i}\right) \sum_{j=1}^{N_{i}} \frac{q_{1}^{i j}}{q_{1}^{i}}\left(z_{21}^{i j}-z_{11}^{i j}\right) \\
& +\sum_{i=1}^{s}\left(q_{2}^{i}-q_{1}^{i}\right) \sum_{j=1}^{N_{i}} \frac{q_{1}^{i j}}{q_{1}^{i}}\left(\left[z_{22}^{i j}-z_{21}^{i j}\right]-\left[z_{12}^{i j}-z_{11}^{i j}\right]\right) \\
& +\sum_{i=1}^{s} q_{1}^{i} \sum_{j=1}^{N_{i}} z_{22}^{i j}\left(\frac{q_{2}^{i j}}{q_{2}^{i}}-\frac{q_{1}^{i j}}{q_{1}^{i}}\right)+\sum_{i=1}^{s} q_{1}^{i} \sum_{j=1}^{N_{i}} \frac{q_{1}^{i j}}{q_{1}^{i}}\left(z_{21}^{i j}-z_{11}^{i j}\right) \\
& +\sum_{i=1}^{s} q_{1}^{i} \sum_{j=1}^{N_{i}} \frac{q_{1}^{i j}}{q_{1}^{i}}\left(\left[z_{22}^{i j}-z_{21}^{i j}\right]-\left[z_{12}^{i j}-z_{11}^{i j}\right]\right) \\
& +\sum_{i=1}^{s} q_{1}^{i} \sum_{j=1}^{N_{i}} \frac{q_{1}^{i j}}{q_{1}^{i}}\left(z_{12}^{i j}-z_{11}^{i j}\right) .
\end{aligned}
$$

In eqn $5, z_{k \boldsymbol{l}}^{i}$ (resp. $z_{k l}^{i j}$ ) is the average trait value of species $i$ (resp. of genetic lineage $j$ of species $i$ ) at time point $t_{k}$ in environmental condition $l$, and $q_{k}^{i}$ (resp. $q_{k}^{i j}$ ) is the relative abundance of species $i$ (resp. of genetic lineage $j$ of species $i$ ) at time point $t_{k}$ in the total community. In order of appearance, the terms on the right-hand side of eqn 5 reflect trait change due to species sorting, interaction components between species sorting and lineage sorting, between species sorting and genetic trait change within 
lineages and between species sorting and evolution of plasticity, lineage sorting, genetic trait change within lineages, the evolution of plasticity component, and lastly the plasticity component. Genetic trait change within lineages represents the genetic shifts within genetic lineages that are not detected by molecular techniques (e.g., sequencing the 16S rRNA gene in bacteria), but do result in phenotypic change (GOVAERT et al. 2016).

A reduced version of the PRN equation has been used to assess the contributions of species sorting, lineage sorting and their interaction to temporal change in age at first reproduction of a zooplankton community consisting of three zooplankton species (Daphnia pulex, Daphnia pulicaria and their hybrid) at four different food conditions (GOVAERT et al. 2016). While species sorting was overall the main contributor to the observed change in age at first reproduction, the eco-evolutionary interaction of species sorting $\times$ lineage sorting did show large contributions, and this only in a few treatments, indicating that the importance of eco-evolutionary interactions might depend upon the environmental conditions.

\section{Variation partitioning method of LAJOIE \& VELLEND (2015)}

The variation partitioning method, developed by LEPŠ et al. (2011) and extended by LAJOIE \& VELLEND (2015) to account for continuous environmental gradients, has been extended to quantify effects of the genetic and non-genetic components of intraspecific trait variation (BRANS et al. 2017; LAJOIE \& VELLEND 2018). This method differs from previous partitioning metrics in the focus on partitioning community trait variation into evolutionary and non-evolutionary contributions along an environmental gradient of interest, as opposed to mean community trait change along a time gradient. Hence the contribution found depends on the environmental gradient used. However, note that the environmental gradient can also be a temporal gradient, where species abundances and trait values are measured at multiple time points. In its original formulation, this method quantifies the contribution of intra- and interspecific trait variation to total observed community trait variation by calculating three types of community weighted means (CWMs) for a set of $m$ communities, uniquely indexed as $r \in\{1, \ldots, m\}$ (LAJOIE \& VeLLEND 2015). The first type of CWM uses site-specific species means, and reflects trait variation both due to species sorting (referred to as species turnover (SPT) in LAJOIE \& VELLEND 2015) and to intraspecific phenotypic trait change (referred to as intraspecific trait variation (ITV) in LAJOIE \& VELLEND 2015; $\left.\mathrm{CWM}_{\mathrm{SPT}+\mathrm{ITV}}=\sum_{i=1}^{s^{r}} q^{i r} z^{i r}\right)$. The second type uses fixed species means and reflects trait variation only due to species sorting $\left(\mathrm{CWM}_{\mathrm{SPT}}=\sum_{i=1}^{s^{r}} q^{i r} \bar{Z}^{i}\right)$. The third type is the difference between the previous two, and describes the variation due to intraspecific phenotypic trait variation $\left(\mathrm{CWM}_{\text {ITV }}=\right.$ $\left.\mathrm{CWM}_{\mathrm{SPT}+\mathrm{ITV}}-\mathrm{CWM}_{\mathrm{SPT}}=\sum_{i=1}^{s^{r}} q^{i r}\left(z^{i r}-z^{i}\right)\right)$. The latter term, however, confounds both evolutionary change and phenotypic plasticity.

Each type of CWM is then used as a response variable in a regression analysis against an environmental gradient of interest. From these regressions, regression sums of squares are obtained to assess how much each process (species sorting, intraspecific phenotypic trait change or the combination of both) explains the observed community trait variation along the environmental gradient of interest (LAJOIE \& VELLEND 2015). For example, LAJOIE \& VELLEND (2015) used this method to evaluate the relative importance of intraspecific phenotypic trait change in three functional plant traits (flowering phenology, specific leaf area and height) to non-climatic (soil properties and light) and climatic (elevation) axes for a set of 30 herbaceous plant communities. They found that intraspecific phenotypic trait change had larger contributions along non-climatic axes, and concluded that their result is evidence for the hypothesis that phenotypic plasticity is greatest in response to conditions varying at small spatial scales.

This approach has been extended by BRANS et al. (2017) to assess the contribution of genetic and nongenetic trait change, in addition to effects of species sorting and intraspecific phenotypic trait change, to community change in body size of 83 zooplankton communities along an urbanisation gradient. Here, 
I report a more general version of this extension, and refer the reader to BRANS et al. (2017) for an explanation on how plasticity effects of particular experimental treatments can be additionally included. Consider a phenotypic trait $z$, where $z^{i r}$ denotes the phenotypic value of $z$ for a species $i$ in community $r$. This phenotypic trait value can alternatively be written as the sum of its genotypic value $\left(z_{G}^{i r}\right)$ and the phenotypic plasticity found in the field or to an experimental treatment $\left(z^{i r}-z_{G}^{i r}\right)$, i.e., $z^{i r}=z_{G}^{i r}+\left(z^{i r}-z_{G}^{i r}\right)$. This decomposition can then be substituted in the intraspecific trait variability effect (i.e., $\mathrm{CWM}_{\text {ITV }}$ ) as calculated in the variation partitioning method of LAJOIE \& VELLEND (2015), i.e.,

$$
\sum_{i=1}^{s^{r}} q^{i r}\left(z^{i r}-\bar{z}^{i}\right)=\sum_{i=1}^{s^{r}} q^{i r}\left(z_{G}^{i r}-\bar{z}_{G}^{i}\right)+\sum_{i=1}^{s^{r}} q^{i r}\left(\left[z^{i r}-z_{G}^{i r}\right]-\left[\bar{z}^{i}-\bar{z}_{G}^{i}\right]\right) .
$$

The first term on the right-hand side of eqn 6 is the genetic trait change and the second term is the nongenetic trait change due to plasticity responses in the field or experimental treatment, but could also include ontogenetic changes (see BRANS et al. 2017). BRANS et al. (2017) then modified this extension further to also include data from a common garden experiment on two different temperatures $\left(20^{\circ} \mathrm{C}\right.$ and $24^{\circ} \mathrm{C}$ ), which made it possible to account for the effect of plasticity due to temperature. They found that the change in body size of the zooplankton communities along the urbanisation gradient could be largely explained by non-genetic intraspecific trait change. LAJOIE \& VelLEND (2018) have also extended the SPT + ITV partitioning by including data information on a transplant experiment in the regression model. This also makes it possible to quantify the amount of community trait variation that can be explained by plasticity, or by genetic effects. They applied this extension to a set of plant communities sampled along an elevation gradient, and found that phenotypic plasticity was an important contributor to intraspecific phenotypic trait change in plant height, specific leaf area and leaf area. However, in both studies phenotypic plasticity was only assessed for one species.

The main assumption of this method is that the regression sums of squares obtained with the different CWMs as response variable are comparable. This is the case when the response variables are on the same scale. This also means if one CWM is transformed (e.g., to normalize the response data), then all CWMs should undergo the same transformation. Moreover, in the case of multiple predictor variables, the same predictors and their interactions should be captured in the model of each CWM in order to compare regression sums of squares across these models. However, the best fitted model for each CWM may differ in the transformation of the response variable as well as in the predictor variables explaining the variation observed in a particular CWM. If this is the case, it is, however, unclear how this approach should be applied.

\section{Comparison of partitioning metrics}

With the current increase of eco-evolutionary partitioning metrics, there is a pressing need for an assessment of how these methods differ in their quantification of ecological and evolutionary processes. This will help scientists to determine which method is best for their study while taking limitations of the method used into account.

\section{The Price, reaction norm and Price-Reaction-Norm equation}

The Price equation, the reaction norm approach and the Price-Reaction-Norm equation have been compared with one another in a study by GOVAERT et al. (2016). In this study it was revealed that the Price equation was not able to separate genetic trait change and evolution of plasticity within lineages from phenotypic plasticity, while the reaction norm approach, which uses species means, attributed lineage sorting to both constitutive evolution and evolution of plasticity. An advantage of using species means as opposed to genetic lineage means is that the reaction norm approach is more easily applicable to sexually reproducing species. While PRICE (1970) himself stated that his equation holds for both sexual and asexual reproduction, it is not straightforward to apply the Price equation to disentangle trait 
change in a sexually reproducing population. This is because, in order to use the Price equation, one needs to categorise the ancestral population. This categorisation then determines to which categories the descendants belong, which means that the indexing of the descendants is linked to the ancestral grouping (LYNCH \& WALSH 1998; FRANK 2012). With sexually reproducing species, a descendant individual can be linked to two ancestral individuals. Therefore, if the two ancestral individuals belong to a different category, it is not clear to which category the individual descendant should be linked. On the contrary, for asexually reproducing populations, descendant individuals can be linked to one ancestral individual, and the categorisation can be chosen as subsets of lineages. As a partial solution to this problem, KERR \& GODFREY-SMITH (2009) extended the Price equation to include a connectivity variable that allowed more complex connections between parents and offspring. If information on the connection between parents and offspring is available (e.g., via molecular markers or controlled siredam experiments; JONES et al. 2010), then this extension could be used to allow for a better inclusion of sexually reproducing populations in the Price equation. If no such information is available, one could still use the Price or Price-Reaction-Norm equation to sexually reproducing species, assuming that a meaningful grouping within species can be made. For example, one could choose groups of particular genotypes (e.g., coat colour of wolfs, COULSON et al. 2011; or groups of particular families). This would, however, change the interpretation of some components: i.e., lineage sorting would now reflect the sorting of the group chosen (e.g., genotype sorting).

In the same study, GOVAERT et al. (2016) also compared the community recursive version of the Price equation (ARNOLD \& FRISTRUP 1982; GOVAERT et al. 2016) with the Price-based version of COLLINS \& GARDNER (2009) and found that these methods differed from each other in their attribution of the species $\times$ lineage sorting component (GOVAERT et al. 2016). In the community recursive version of the Price equation this interaction component is attributed to the species sorting component, while in the Price-based equation of COLLINS \& GARDNER (2009) it is attributed to the lineage sorting component. The methods thus give a different outcome when both processes of lineage and species sorting are present in the biological system under study. Both solutions are, however, wrong as these metrics either confound species sorting with an eco-evolutionary interaction or lineage sorting with and ecoevolutionary interaction.

\section{The quantitative genetic animal model, metric of ELLNER et al. (2011), age-structured Price equation and integral projection modelling}

In a study by VAN BENTHEM et al. (2017), four other frameworks were compared - the quantitative genetic animal model (HENDERSON 1950), the 'Geber' method (HAIRSTON et al. 2005; ElLNER et al. 2011), the age-structured Price equation (COULSON \& TULJAPURKAR 2008) and the integral projection model (EASTERLING et al. 2000) - using simulated scenarios with and without selection on body size and with high and low heritability of body size to decompose changes in body size into evolutionary, plasticity and demographic effects. It has been shown earlier that the age-structured Price equation can also be used to track moments of character distributions similar to the ones described in an (agestructured) integral projection model (COULSON et al. 2010). The study of VAN BENTHEM et al. (2017) shows that the differences found between the four methods are mostly due to differences in aims and definitions, but also which processes they ascribe to plasticity and how they take demography into account. Moreover, VAN BENTHEM et al. (2017) showed that the age-structured Price equation and the integral projection model capture selection, whereas the quantitative genetic model and the 'Geber' method rather quantify the response to selection. As all frameworks compared in VAN BENTHEM et al. (2017) have been developed independently, they differ in their assumptions, results and interpretation, and none of them gives the 'true' contributions of the underlying processes (VAN BENTHEM et al. 2017). Similar to a conclusion made in GOVAERT et al. (2016), VAN BENTHEM et al. (2017) concluded that different research questions require different frameworks, and researchers need a thorough understanding of the differences between the available frameworks to select the appropriate method for their question. 
With the increasing interest in contemporary ecological and evolutionary dynamics, more metrics will likely be developed in the future. It is important that these methods are also compared with existing methods, to indicate how they differ and which question they can answer.

\section{Metric of ELLNER et al. (2011) and reaction norm approach}

In addition to the comparisons made in previous studies, I briefly compare here the discrete version of the method of ELLNER et al. (2011) with the reaction norm approach developed in GOVAERT et al. (2016). However, more technical details can be found in Supplementary file B. The metric of ELLNER et al. (2011) was originally developed to quantify the contributions to change in an ecological variable, while the reaction norm approach was originally developed to quantify contributions of plasticity and evolution to phenotypic trait change. Both methods, hence, relate to one of the two goals of partitioning methods in eco-evolutionary dynamic studies. However, both methods make use of reaction norms, either at the level of the ecological variable (for the 'Geber' method; HAIRSTON et al. 2005), or at the level of the phenotypic trait (for the reaction norm approach; GOVAERT et al. 2016) or both ('PriceGeber' method; ELLNER et al. 2011). It is important to note that both methods can be used to partition effects of ecology and evolution to observed trait change as well as to change in an ecological response variable (detailed in Supplementary file B). The latter being valid for all partitioning metrics: i.e., whenever direct measurements of an ecological variable are available, it can be similarly used as a phenotypic trait in most of the previously described partitioning metrics. Exceptions to this are when the ecological variable cannot be related to individuals or specific groups (e.g., population growth); then only approaches that use population means can be used.

Both the metric of ELLNER et al. (2011) and the reaction norm approach can be retrieved by solving the least-squares normal equation for the model coefficients of a regression model in which trait $z$ or an ecological variable $X$ is used as a response variable in function of two indicator variables representing the genetic and ecological states at time points 1 and 2. The main difference is, however, whether and how an interaction component is included, which also alters the interpretation of the components (see Supplementary file B). While the reaction norm approach calculates its components compared to an ancestral population (i.e., the oldest time point), the metric by ELLNER et al. (2011) can be obtained by using a midpoint as reference (PANTEL et al. 2015). Therefore, the method of ELLNER et al. (2011) can also be interpreted as quantifying average effects of evolution and ecology to trait change (Fig. 4a), as opposed to effects of ancestral plasticity, evolution of trait mean, and evolution of plasticity (Fig. $4 \mathrm{~b}$ ). The latter reflecting an evolved plasticity response from the ancestral plasticity as described in the reaction norm approach.

Both methods have been extended to address more complex cases. For example, the method of ELLNER et al. (2011) has been extended to incorporate multiple ecological and evolutionary components. This extension has been used in PANTEL et al. (2015) to show that the effect size of evolution (i.e., adaptation of D. magna to fish or macrophytes) on community composition was similar to the effect of the two ecological factors (i.e., presence of fish and macrophytes) and by PIGÉON et al. (2017) to quantify the effects of heritable and non-heritable changes in body mass distribution versus age structure, population density and climate effects on survival, recruitment and population growth in wild bighorn sheep. While the reaction norm approach can also be extended to include multiple components, it is at this moment still unclear what these components actually mean (but see Supplementary file C). On the other hand, the reaction norm approach has been extended to partition community trait change into ecological and evolutionary components (GOVAERT et al. 2016), while this is less obvious for the metric of ELLNER et al. (2011). For the latter, ways of extending the method of ELLNER et al. (2011) to community data should be explored. Having methods available that partition community trait change into ecological and evolutionary components is important, because observed community trait changes might be the result 
of both species sorting and species' evolution, separately or combined (COLLINS \& GARDNER 2009; BARRACLOUGH 2015).

\section{Eco-evolutionary interactions}

Different eco-evolutionary partitioning metrics allocate different evolutionary and non-evolutionary processes. For example, the original version of the Price equation, the method of ELLNER et al. (2011) and the one of COLLINS \& GARDNER (2009) only evaluate main effects of ecology and evolution, while it is well known that intertwined interactions between ecology and evolution, such as evolution of plasticity or an interaction between species sorting and evolution, may also play an important role in explaining the observed trait change. Evolution of plasticity can occur when there is genetic variation present for phenotypic plasticity (DAY et al. 1994; NEWMAN 1994), and hence an evolved change in the response of plasticity can shift the impact plasticity had on the population or community variable. The interference between species sorting and evolution has been shown empirically (e.g., FUKAMI et al. 2007; DE MEESTER et al. 2007; PANTEL et al. 2011; FARKAS et al. 2013) and theoretically (e.g., URBAN et al. 2008; Loeuille \& Leibold 2008; Urban \& De MeEster 2009). For example, De MeESTer et al. (2007) found that the establishment success of non-D. magna zooplankton species immigration was influenced by the genetic composition of the resident D. magna populations. However, unlike evolution of plasticity, it is not well-studied, but is a core part of eco-evolutionary dynamics at the community level. Partitioning metrics, such as the reaction norm approach and the Price-Reaction-Norm equation do include such eco-evolutionary interactions between species sorting and evolution, and might provide important steps to a better understanding of the importance of these interactions. While an eco-evolutionary interaction

(a)

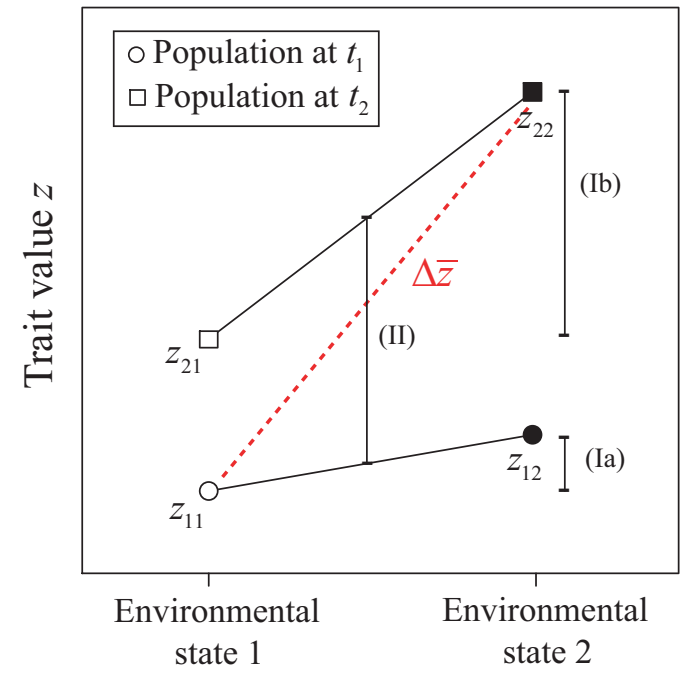

(b)

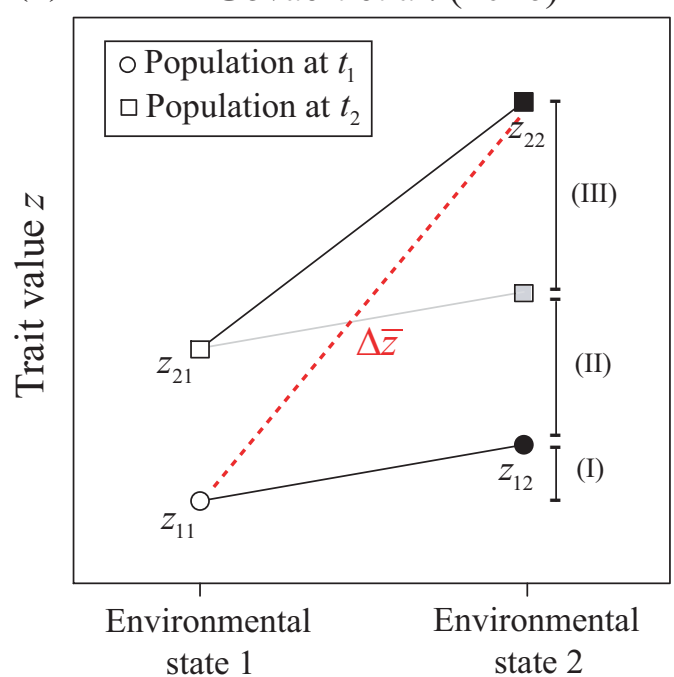

Fig. 4 - Visualisation of the ecological and evolutionary effects quantified by the metric of ELLNER et al. (2011) and of GOVAERT et al. (2016) to observed population trait change. Graphs display the population mean reaction norms at time point $t_{l}$ (circles) and $t_{2}$ (squares), where each time point corresponds to a specific environmental condition (e.g., low and high nutrients, absence and presence predator). Unfilled symbols represent the population mean trait at environmental condition 1 (i.e., the environmental condition at time point $t_{1}$ ), and filled symbols represent the population mean trait at environmental condition 2 (i.e., the environmental condition at time point $t_{2}$ ). (a) The original formulation of the metric of ELLNER et al. (2011) quantifies the main effect of environment (average of (Ia) and (Ib)) and of evolution (II). (b) The original formulation of the metric of GOVAERT et al. (2016) quantifies effects of (ancestral) plasticity (I), constitutive evolution (II) and evolution of plasticity (III). The gray filled squares gives the expected population trait mean at time point $t_{2}$ when no evolution of plasticity occurs. 
component can also be included in the method of ElLNER et al. (2011) (Supplementary file B), it is not always straightforward to interpret this component.

\section{The appropriate method for a study}

Metrics clearly differ in the processes they allocate and the data information they need. Is the best metric the one that can quantify more and the most accurate processes, or the one that best answers the question asked? Which metric is better suited highly depends on the organisms used, the processes of interest and the question asked. For example, for asexually reproducing species, the Price-Reaction-Norm equation gives a more accurate partitioning into ecological and evolutionary components contributing to population or community trait change. A downside of methods quantifying more processes is often the high amount of data needed. For example, for the Price-Reaction-Norm equation one needs to measure individuals of each genetic lineage at the environmental conditions of the time points to which trait change is occurring, allowing the construction of reaction norms for each lineage. However, note that a reduced version of this metric is also available (see GOVAERT et al. 2016). In general, the PriceReaction-Norm equation should be favoured over the original formulation of the Price equation, as it allows the quantification of eco-evolutionary interactions. As soon as all information for the Price equation is available, the simplified version of the Price-Reaction-Norm approach can also be used.

Obtaining information on reaction norms for each genetic lineage is often not possible or not necessary (e.g., in the case of sexually reproducing species). For example, the reaction norm approach and the metric of ELLNER et al. (2011) use population mean reaction norms. This makes these metrics applicable to both sexually as asexually reproducing species. However, it is only for the reaction norm approach that a clear community-level extension including species sorting is available. The reaction norm approach has the advantage that it also provides information on evolution of plasticity. When no common garden or transplant experiments are feasible (e.g., for some large mammal species), quantitative genetic animal models can provide a solution when individual-level data is available. These models allow the decomposition of phenotypic variation into a genetic and an environmental component (RÉALE et al. 2003; WILSON et al. 2010), and can be combined with partitioning metrics (e.g., PIGÉON et al. 2017). The available data and the processes of interest will in the end often be key determinants in choosing the appropriate metric for a study.

\section{Practical guidelines on...}

The increase in the diversity of partitioning metrics becoming available makes it difficult for researchers to match their question and dataset to a specific metric. It is important that the choice of the ecoevolutionary partitioning metrics matches both the available data and the hypothesis of interest, and that researchers are well aware of the limitations of the metric used as well as the consequences of not having fully resolved data. As a guideline, I constructed a simple decision tree using a few basic questions to provide an initial aid kit for researchers to decide which partitioning metrics might be suitable for their study system (Figs 5-6), and provided a schematic figure on the data requirements for the metrics discussed in this study (Fig. 7). I here do not focus on the type of data needed for integral projection models or quantitative genetic models. For these types of data I refer the reader to the study of VAN BENTHEM et al. (2017).

\section{... population metrics}

Depending on the data collected to study population trait change, different sets of metrics are available. Throughout the decision trees one determines whether sets of genetic lineages or another meaningful grouping (e.g., genotype grouping in case of sexually reproducing species) can be defined, if trait values or relative abundances are collected or known (e.g., from literature) and if these can be linked to the groups, and whether reaction norms can be constructed. For example, if individual trait measurements are taken 


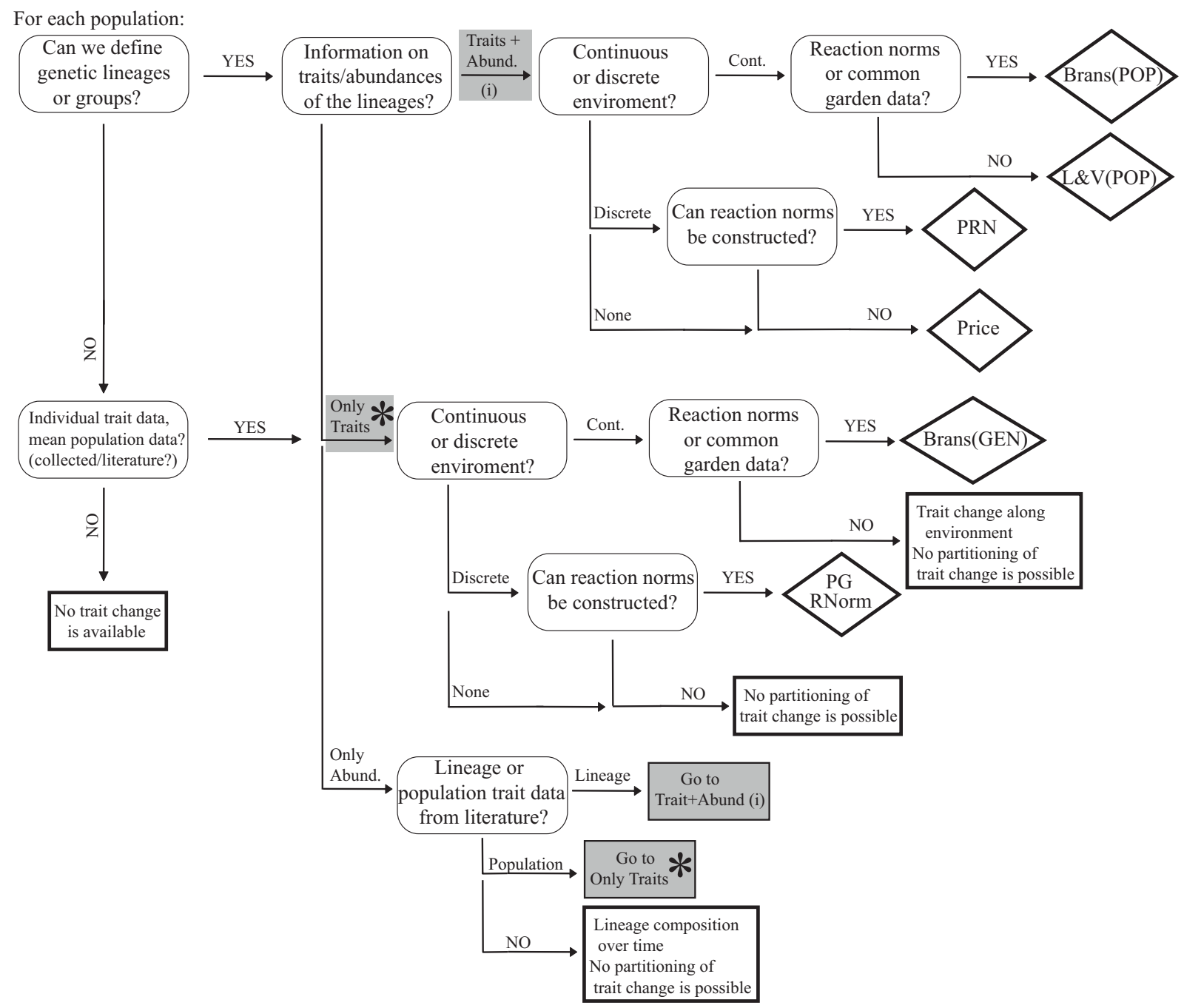

Fig. 5 - Decision tree showing relationship between what is known about a system at the population level and the appropriate eco-evolutionary partitioning metric. For each population one first decides whether meaningful groups can be identified: sets of clonal individuals of an asexually reproducing species (e.g., in Daphnia), sets of individuals grouped using molecular markers (e.g., bacteria) or even groups of individuals that share a particular genotype or some family structure. Depending whether information on the trait values and abundances of these groups are known and whether reaction norms can be constructed the available metric may be the Price equation (Price), the Price-Reaction-Norm equation (PRN), the reaction norm approach (RNorm), or the method of ELLNER et al. (2011) for discrete data (PG: 'Price-Geber'; detailed in ELLNER et al. 2011). The first two are only possible if different groups within the population can be assessed. Whenever the PRN equation can be used, one can also use the reaction norm approach or the metric of ELLNER et al. (2011). If information along a continuous environmental gradient has been collected, then the method of Lajoie \& Vellend (2015) at the population level (see main text) can be used L\&V(POP). If common garden data is collected and abundances of lineages are known then the extended version in BRANS et al. (2017) at the population level can be used (Brans(POP)) or in the absence of lineages abundances one could still assess genetic versus non-genetic effects along the environmental gradient (Brans(GEN)). If only trait values are available and no reaction norms can be constructed then depending whether different groups can be assessed, one can only look at trait change over time at the population level (no partitioning into genetic and non-genetic components is possible) or at the within-group level (trait change within lineages over time). If only abundances are available and groups can be constructed then one can look at the change in lineages composition over time. 
that correspond to different genetic lineages or clonal lines within an asexually reproducing population (or during the asexual reproduction phase of an organism, e.g., in Daphnia species) and information on the relative abundances of these lineages or groups is known, then the Price equation with or without interaction component can be used to quantify lineage sorting versus trait change within lineages (Fig. 7). If in addition, trait values are measured at two environmental conditions corresponding to the discrete time points using a common garden or transplant experiment, thus allowing the construction of reaction norms for each lineage, then the Price-Reaction-Norm equation can be used (Fig. 7). If it is impossible to link the trait values to the genetic lineages or groups of a particular species, or no information on their relative abundance is known, the trait values of these individuals may be pooled to an unweighted average population trait value. Hence population mean reaction norms can still be constructed, which allows the use of the reaction norm approach and the metric of ELLNER et al. (2011) (Fig. 7).

The partitioning method of LAJOIE \& VELLEND (2015) and its extension given in BRANS et al. (2017) can also be used at the population level, whenever populations are sampled along a continuous environmental gradient (Figs 5, 7). If field data are complemented with common garden data, one can compare the regression result obtained using field data to the result obtained using common garden data. The difference would assess plasticity and ontogenetic effects from the field (BRANS et al. 2017). If information on lineage abundances is known, one could additionally assess lineage turnover and intra-lineage trait variation. If no common garden data are available in addition to field data, but lineage abundances are known, it is still possible to use a population version of the partitioning method of LAJOIE \& VELLEND (2015). Here, population trait variation will be separated into lineage turnover and intra-lineage trait variation among populations (as opposed to intraspecific trait variation among communities).

\section{... community metrics}

At the community level, similar types of data as at the population level might be available for the member species in the community. If the species of the communities consist of distinct genetic lineages

Fig. 6 (opposite page) - Decision tree showing relationship between what is known about a system at the community level and the appropriate eco-evolutionary partitioning metric. For each community one first decides whether each member species can be subdivided in groups (e.g., genetic lineages). In next steps one determines whether trait values and abundances are collected or known for the different species and/or genetic groups within species, whether information about environmental gradients is known and if this is continuous or discrete, and whether reaction norms can be constructed. Depending on the answer, the metric used can be the Price equation (Price), the Price-based method of ColLINS \& GARDNER (2009) (C\&G), the Price-Reaction-Norm equation (PRN), the reaction norm approach (RNorm), the metric of ELLNER et al. (2011) for discrete data (PG: Price-Geber; detailed in ELLNER et al. 2011), the SPT+ITV-partitioning approach of LAJOIE \& VELLEND (2015) if a continuous environmental gradient is present (L\&V) or the method of LEPŠ et al. (2011) if discrete environments are present (Leps). If in addition common garden data are available then the extension in BRANS et al. (2017) can be used (Brans). In case of the SPT+ITV-partitioning method of LAJOIE \& VELLEND (2015), if only species mean trait data are available then one can only determine species turnover ( $\& \mathrm{~V}(\mathrm{SPT}))$. If only species trait and abundance data is available then a Price equation at the community level can still be used (Price (COM)). If only species trait data is available and no reaction norms can be constructed then one can still look at trait change over time, but no partitioning into ecological and evolutionary components is possible. If only trait values of genetic lineage is available, then depending whether additional information on species abundances is available, one can either go to 'Trait+Abund. Species (iii)' or to the decision tree for populations (go to *) in Fig. 5. If only species abundance data is available and no reaction norms can be constructed, then one can still determine the change in species composition over time, but no partitioning into ecological and evolutionary contributions is possible. 
For each community:

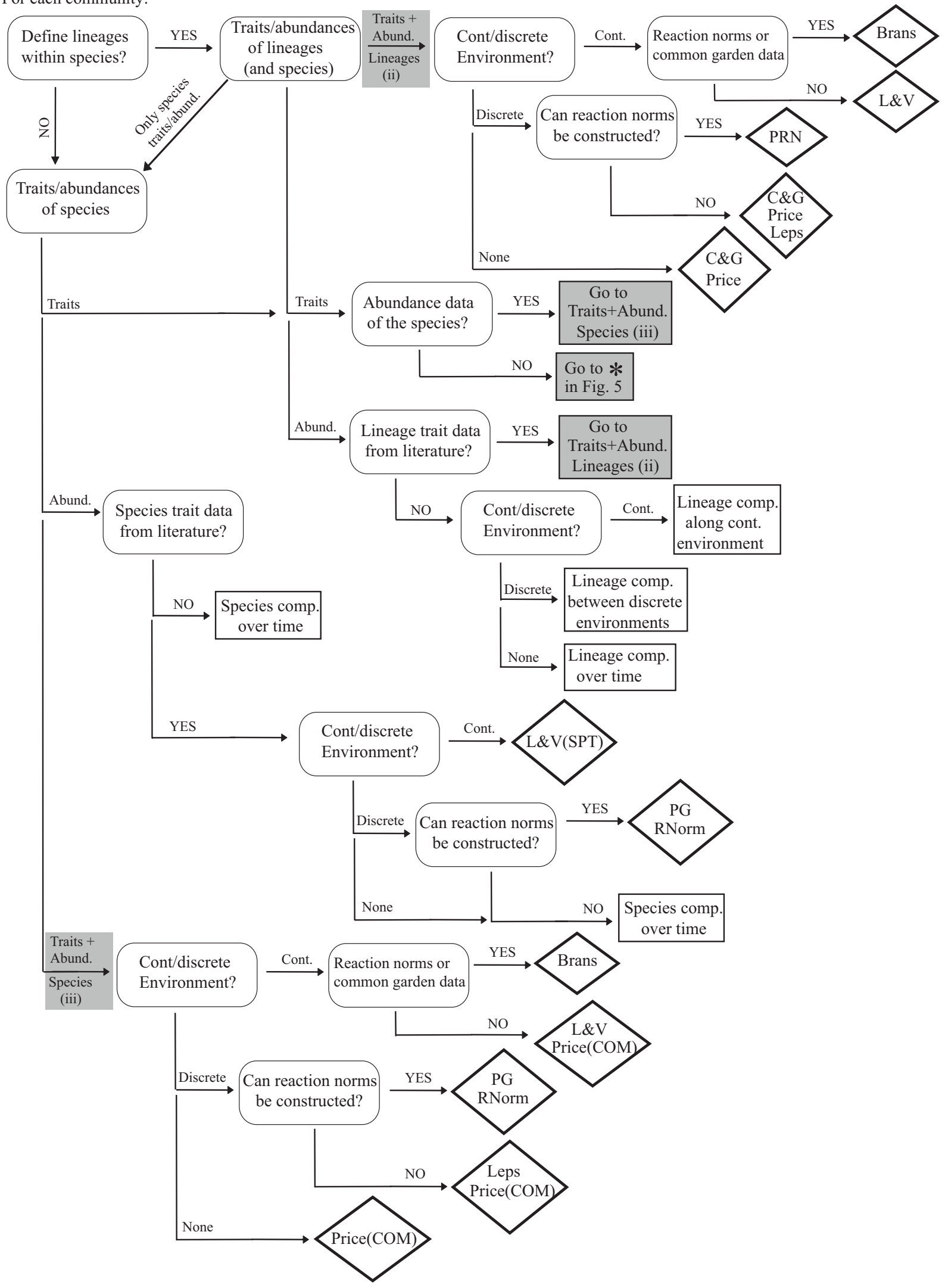



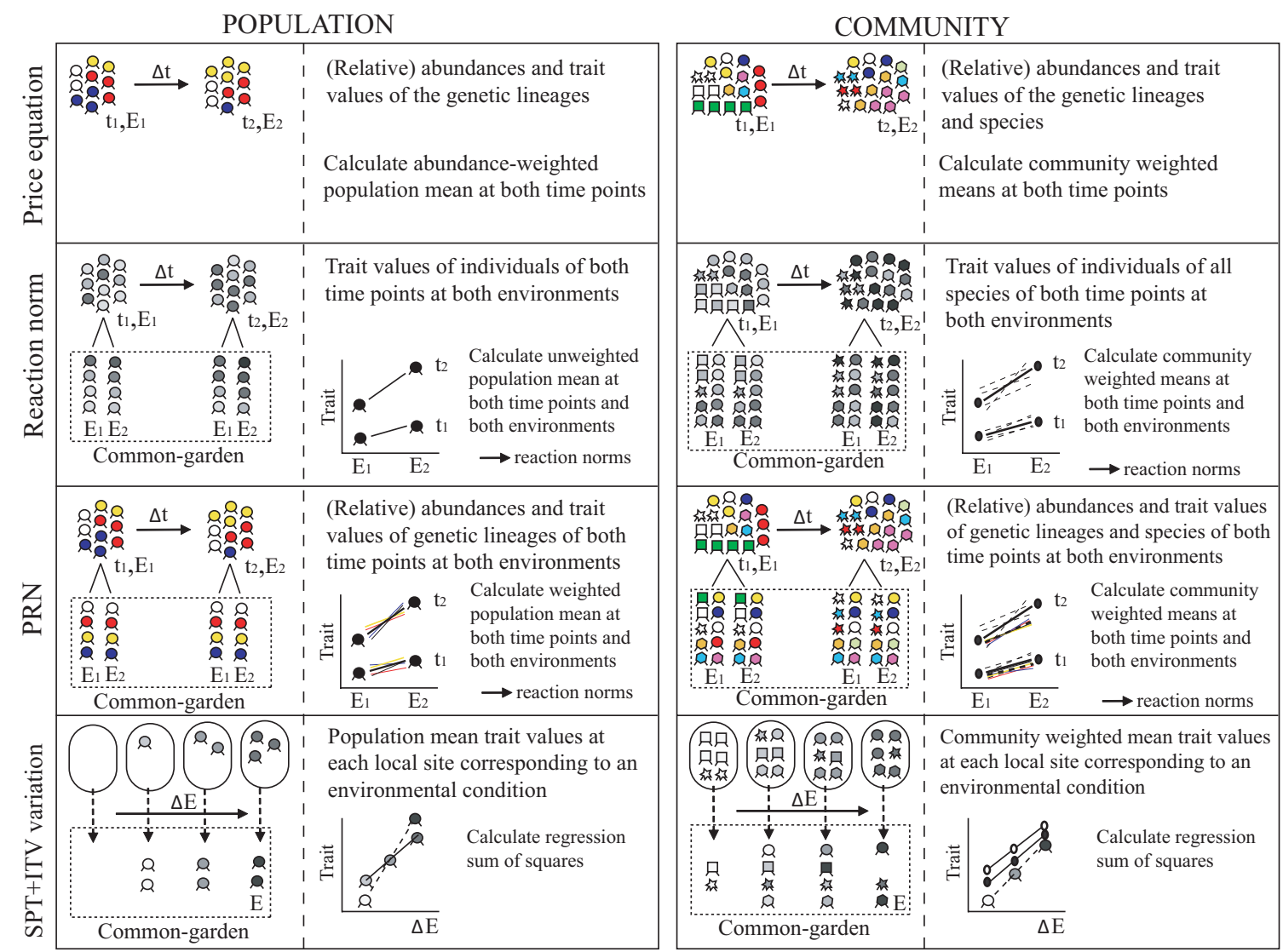

Fig. 7 - Schematic overview of the data requirements for the Price equation, the reaction norm approach, the Price-Reaction-Norm (PRN) equation and the SPT+ITV-partitioning method of LAJOIE \& VELLEND (2015) at the population and community level. $\Delta t$ refers to a temporal change from time point $t_{1}$ to time point $t_{2}$ corresponding to a change from environmental condition $E_{1}$ to $E_{2}$. $\Delta E$ corresponds to an environmental gradient. At the population level for the Price equation and the PRN equation, the different colours represent different genetic lineages in an asexually reproducing population. Note that the colours may also refer to a specific grouping within the population or species (e.g., groups related to specific genotypes or family structure). For the reaction norm approach and the SPT+ITV-partitioning method, individuals are represented in grey colours, indicating that these approaches do not necessarily use information on lineage abundances. For the reaction norm approach, at the population level, if information on lineages is present one can calculate lineage-weighted population means. If this information is not present, then one results to the original formulation, and calculates unweighted population means. However, at the community level, one always calculates the community means weighted by species abundances, while for some approaches the species trait means can be unweighted means (e.g., in the reaction norm approach). The different symbols at the community level are used to represent different species that can each consist of different genetic lineages (represented by the colours) or different phenotypes not related to a specific grouping (represented by grey colours). For the reaction norm approach and the PRN equation, a common garden experiment is performed to collect data information on the trait values of the different genetic lineages and/or species from both time points at both environmental conditions in order to construct reaction norms. The coloured lines in the reaction norm plot in the PRN equation represent the reaction norms for the individual lineages. Similarly, the dashed lines in the reaction norm plots at the community level for the reaction norm approach and the PRN equation represent the reaction norms for the individual species. When a common garden experiment is performed for the SPT+ITV-partitioning method an extended version, given in BRANS et al. (2017), can be used to quantify genetic and non-genetic components of intraspecific trait variation. At the community level, regression models can be made using the common garden data of all species (white filled symbols) or for an individual species (given by the circles). 
or groups and both trait values and abundances are available for these groups, then depending if reaction norms can be constructed, one can use the Price-Reaction-Norm equation, the Price equation, the metric of COLLINS \& GARDNER (2009), or the metric of LEPŠ et al. (2011). If only trait values are known, then an eco-evolutionary partitioning can be performed for each species separately (i.e., go to the decision tree for populations; previous section; Fig. 5). If only information on abundances is known for the lineages, then no eco-evolutionary partitioning can be performed, but one can only track the changes in lineage composition along time. If no genetic grouping within species can be constructed, then one can use the reaction norm approach, the metric of ELLNER et al. (2011), the method of LEPŠ et al. (2011) or the Price equation at the commmunity level. The method used will depend on whether reaction norms can be constructed. If only species abundances are known, then no eco-evolutionary partitioning can be performed, and one can only look at the change in species composition along time.

There also exist studies that collected local trait values and abundances of species within communities along environmental gradients (Fig. 7). These types of studies do not necessarily seek to understand temporal trait change, but rather trait variation among community weighted means given an environmental gradient. These studies can then use the classical SPT+ITV-partitioning approach given by LAJOIE \& VELLEND (2015) to assess the contribution of species turnover (SPT) and intraspecific trait variation (ITV) to total trait variation along the environmental gradients. If in addition common garden or transplant data were collected one could use the extended version by BRANS et al. (2017).

\section{... collecting community data}

While partitioning metrics at the community level have become increasingly available, to date we generally still lack community trait data suitable to assess both main and interaction effects of ecology and evolution as given by the reaction norm approach and the Price-Reaction-Norm equation, which makes it difficult to draw conclusions about the quantitative importance of evolution compared to ecology for changes in community trait values. These metrics require trait measurements on multiple individuals of the constituent species of the community in conditions corresponding to the environmental change between the time points (Fig. 7). Collecting suitable data describing temporal change in plant, animal or microbe communities experiencing varying environmental conditions is, however, challenging. The main challenge involves tracking abundances and trait changes of multiple species comprising a community (BARRACLOUGH 2015). Species can vary in their trait values due to demographic (e.g., age structure), plasticity and genetic effects (OzGUL et al. 2009) and can vary in their (relative) abundances over time, changing the strength of species interactions, which makes it difficult to measure these values and interactions experimentally (BARRACLOUGH 2015). However, several approaches such as wholecommunity resurrection, repeated sampling in nature or in experimental evolution settings, or space-fortime substitutions might provide opportunities to collect the right amount of data needed.

\section{Resurrection ecology}

In a community context, studies have been using resurrection ecology (i.e., revival of individuals from the past via hatching of dormant life stages; KERFOOT et al. 1999; KERFOOT \& WEIDER 2004) to determine how past community composition shifted due to environmental changes (e.g., REINEMANN et al. 2009; ARSENAU et al. 2011). However, so far, these studies have not included assessments of trait values of the member species of the communities at the different time periods using common garden approaches, which is the type of information needed for the reaction norm approach. In future studies, it would be valuable to hatch multiple (e.g., all common) species of the communities from the sediment core at the time periods of interest. Trait values for different individuals from particular groups of each species could then be measured under multiple environmental conditions (e.g., a control and fish kairomone condition, STOKS et al. 2016). Together with quantifying the changes in relative abundances of the different species through time, this would allow an assessment of the community trait change under e.g., shifting fish predation pressure. 


\section{Experimental evolution}

Information on changes in the mean value of a trait over time or trait evolution under controlled laboratory conditions can be found in many studies (e.g., Darwin finches on the Galápagos islands, GRANT \& Grant 2002; Soay sheep on St. Kilda, ClutTON-Brock \& PEMBERTON 2004; experimental evolution on the gut bacterium Escherichia coli, ELENA \& LENSKI 2003). However, fewer studies have focused on the repeated and simultaneous sampling of multiple species comprising a community, either in natural or experimental conditions. Few exceptions exist, such as the experimental study by WEIDER et al. (2008), LAWRENCE et al. (2012) and FiEgNA et al. (2015). For example, in the experimental study by WeIDER et al. (2008), a Daphnia community consisting of three species (i.e., Daphnia pulex, Daphnia pulicaria and their hybrid species) was exposed to four different food conditions, and densities of two clones per species were tracked through time. In order to apply the Price-Reaction-Norm equation with all its estimates of each ecological, evolutionary and eco-evolutionary interaction component to the data collected by WEIDER et al. (2008), it would have required clonal trait measurements before the start and at the end of the experiment in a common control condition. This would have allowed the construction of reaction norms and the assessment of phenotypic plasticity and evolution of plasticity throughout the experiment. Additionally, for those time points at which relative abundances were measured, again, clonal trait values should have been measured in both the control and experimental condition. While one might expect that the genotypic trait value of the Daphnia clones would not change throughout the experiment given the low number of generations involved, in some systems (e.g., bacteria) mutations may have strong impacts on the genetic lineage trait value even over short time spans (LENSKI et al. 1991; ELENA \& LENSKI 2003; LAWRENCE et al. 2012).

\section{Space-for-time substitution}

An approach that could be used to circumvent the need to measure temporal dynamics is a space-fortime substitution (PICKETT 1989) such as a chronosequence approach (STEVENS \& WALKER 1970). This technique involves the use of spatial data to infer temporal dynamics. The spatially separated sites chosen are based on their ecological or environmental gradients and serve as a proxy to predict temporal dynamics (PICKETT 1989). In the chronosequence approach, spatially different forested sites are chosen that share similar attributes (e.g., parent material or substrate), but differ in age (STEVENS \& WALKER 1970; HARDEN 1982; WALKER et al. 2010). A critical aspect in this approach is that the communities at the younger sites are assumed to be developing in a temporal pattern that resembles how the older sites were developed (WALKER et al. 2010). In other studies, the spatial gradient chosen might for example reflect the environmental change expected to occur over time. For example, in a study by ETTERSON \& SHAW (2001), a space-for-time substitution was used to evaluate the evolutionary response of the partridge pea, Chamaecrista fasciculata, to climate change. Populations of C. fasciculata were sampled at three different sites in the U.S. Great Plains across an aridity gradient (i.e., Minnesota, Kansas, and Oklahoma). The spatial gradient among the sites was used as a proxy for the temporal trend expected from global warming. Individual plants from each of the three populations were transplanted among the three sites, and a set of traits was measured. While this study only focused on a single species, a similar approach could be used for communities.

Other studies using a space-for-time substitution have collected individuals of species at different sites, and measured their trait values in either a common environment or in a set of common experimental treatments (e.g., DINH VAN et al. 2014), or have transplanted individuals among ecologically contrasting sites (e.g., ETTERSON \& SHAW 2001; GASOL et al. 2002; NOOTEN et al. 2014). The combination of a space-for-time substitution followed by common garden or transplant experiments with the measurement on species abundances might allow the collection of the type of community data suitable for community partitioning metrics such as the reaction norm approach and the Price-Reaction-Norm equation. Such a combination has been used in a previous study by ELLNER et al. (2011) where they used the data obtained from mesocosm experiments by BASSAR et al. (2010) to measure local adaptation of 
Trinidadian guppies to different predation levels. More specifically, ELLNER et al. (2011) quantified contributions of evolution and ecology to observed changes in several ecosystem features assuming the experiment mimicked consequences of predator introduction. However, in this study only one species was transplanted, the Trinidadian guppy, and not multiple species of the community.

\section{Discussion}

It is now well-documented that evolution can significantly alter ecological processes (reviewed in DAY 2005; FUSSMANN et al. 2007; TURCOTTE et al. 2011) leading to contemporary interactions between ecology and evolution (SCHOENER 2011; HENDRY 2017). With the increase of studies gathering evidence of this two-way interaction between ecology and evolution, there is a growing interest in the development and identification of methods that can quantify the relative importance of evolution compared to ecology in these dynamics. Because evolutionary biology and community ecology have been studied in isolation, their theories were largely developed independently (JOHNSON \& STINCHCOMBE 2007). As a consequence, there are only a few guidelines available as to when and where to expect stronger contributions of evolution or species sorting in structuring community trait composition in natural landscapes. Having effective eco-evolutionary partitioning metrics can help us in building a database on ecological and evolutionary contributions to trait change in different landscapes and environmental gradients and for organism groups with widely different characteristics.

A frequently asked question in eco-evolutionary dynamics is how relatively important is the contribution of ecology and evolution to observed population and community trait changes (HAIRSTON et al. 2005; POST \& PALKOVACS 2009; Ellner et al. 2011). Attempts to answer this question have led to the development of different methods. To date, researchers can use a handful of tools to determine the (relative) importance of ecology and evolution to observed trait change in their study system: quantitative genetic animal model (HENDERSON 1950), the Price equation (PRICE 1970; COULSON \& TULJAPURKAR 2008; COLLINS \& GARDNER 2009), metrics based on reaction norms (ELLNER et al. 2011; STOKS et al. 2016; GOVAERT et al. 2016), integral projection models (EASTERLING et al. 2000; COULSON et al. 2011), and an extension of the method of LAJOIE \& VELLEND (2015) (BRANS et al. 2017; LAJOIE \& VelLeND 2018). Partitioning metrics are designed to be generally applicable. However, some systems might lend themselves more naturally to the collection of suitable data for these metrics. For example, asexually reproducing populations may allow the tracking of genetic lineages through time (needed for the Price equation), or the measuring of individuals from the same genetic lineage at different environmental conditions, resulting in reaction norms (needed for the Price-Reaction-Norm equation). Other methods, such as the SPT+ITV-variation partitioning method of LAJOIE \& VELLEND (2015) need site-specific mean species trait values. Nevertheless, any partitioning metric that aims to quantify evolutionary as opposed to ecological contributions to trait change needs to separate genetic from non-genetic effects. Depending on the metric used, separating intraspecific trait change into genetic and non-genetic effects can be done using common garden or transplant experiments, or using quantitative genetic models.

With the increasing number of metrics allocating different processes of trait change, it is important to determine whether these metrics correctly isolate and quantify the mechanisms of the underlying trait change. At present a major critique of eco-evolutionary partitioning metrics might be that they always yield a 'result', but depending on which metric is used, a different contribution of evolution might be found (e.g., $4=2+2$ or $4=1+3$ ). The latter has been illustrated in GOVAERT et al. (2016) and VAN BENTHEM et al. (2017). Both studies applied a set of different metrics to various simulated data sets and reported that the contribution of evolution found depended on the metric used. Depending on the data available, one might want to use the most detailed partitioning metric. However, this might strongly depend on which processes the researcher wants to allocate. For example, in GOVAERT et al. (2016), the Price equation and a reduced version of the Price-Reaction-Norm equation were applied to a study of WEIDER et al. (2008). Using the Price equation they found that species sorting was the main contributor 
to the observed trait change, while using the Price-Reaction-Norm equation they showed that for some instances the large contribution of species sorting was actually due to a large contribution of an ecoevolutionary interaction between species sorting and evolutionary change. It is thus important that ecoevolutionary partitioning metrics not be blindly applied and that their results are interpreted carefully in terms of the metric's limitations and may only become meaningful when applied in a particular framework (LUQUE 2017). A downside of using the most detailed partitioning metric, is its data-hungry requirement. However, as illustrated in the decision trees, one does not need the most exhaustive data and the most detailed metric to still explore eco-evolutionary contributions to trait change. In such a case, it is for the researcher to be aware of the limitations of the metric used and what features of the system may be folded together to retrieve a simpler approach. Such approaches are still valuable to further our understanding of the importance of evolution and ecology in eco-evolutionary dynamics, even if not every detail is known.

Because existing metrics are designed to isolate the contributions of specific processes, they have often allocated trait change to an incorrect fraction when other processes also operate. In published ecoevolutionary dynamics studies, these metrics have not always led to a correct partitioning of evolutionary and ecological contributions to ecological processes. This can have two causes: in some cases the authors use data that are not entirely appropriate (e.g., when phenotypic data collected from the field are used to infer exclusively 'evolutionary' contributions), or when the metrics that were developed or applied did not partition the data correctly (GOVAERT et al. 2016). It is therefore important that metrics be validated, but also to assess how different metrics compare with one another. Validation and comparison of metrics will allow us to understand which ecological and evolutionary processes individual metrics can allocate, and why metrics might differ in their outcome. Validation tests can be done by constructing simple numerical examples that reflect varying scenarios in which different processes are absent or present (e.g., GOVAERT et al. 2016), or via computer simulations that may approach more complex systems in which certain processes can be controlled for (e.g., VAN BENTHEM et al. 2017). In addition, by applying the metrics to an increasing amount of controlled laboratory or field experiments in which the processes contributing to trait change are known will provide us with a sense of the variability of outcomes in semi-realistic settings.

The metrics discussed in this study are aimed at quantifying contributions of ecology and evolution to observed population and community trait change as opposed to ecosystem change and this across discrete moments in time. Ecosystem functions (e.g., total biomass, total $\mathrm{CO}_{2}$ flux, total productivity of a system), however, can also be impacted by evolution in a focal species (e.g., SCHWEITZER et al. 2005; LENNON \& MARTINY 2008; FUSSMANN et al. 2007; GRAVEL et al. 2011; MADRITCH \& LINDROTH 2011; URBAN 2013). Species evolution has been found to enhance (e.g., LAWRENCE et al. 2012) or constrain ecosystem functioning (e.g., LOEUILLE 2010), and in one instance shifted the ecosystem to an alternative state (e.g., MATTHEWS et al. 2011). Shifts in community composition can also have large effects on ecosystem properties (e.g., SYMSTAD et al. 1998; ZHENG et al. 2010; WAGG et al. 2014; SPAAK et al. 2017). This implies that ecosystem features can be structured by both evolutionary and ecological processes. There exist studies that focus on partitioning change in ecosystem functions. For example, the study of COOK-PATTON et al. (2011) experimentally manipulated genotypic and species diversity to assess their effect on primary productivity. Other studies have developed partitioning metrics to address shifts in some ecosystem function, albeit not yet extended to include evolutionary changes (Fox 2006; GENUNG et al. 2011). For example, Fox and colleagues (Fox 2006; FOX \& HARPOLE 2008; FoX \& KERR 2012) proposed a method based on the Price equation to partition the change in ecosystem functioning between two sites into three distinct effects: a species richness effect (random loss and gain of species richness; SRE), species composition effect (nonrandom loss and gain of high-or low-functioning species; $\mathrm{SCE}$ ) and a context dependence effect (post-loss changes in the functioning of the remaining species; $\mathrm{CDE}$ ). In this method, the ecosystem functions are calculated as the sum of the functional contributions of the different species present in the system. Although existing eco-evolutionary partitioning metrics 
consider mean trait change and therefore cannot be used for ecosystem variables that are calculated as a summed contribution, the Price-based method of Fox and colleagues entails some promising features. For example, the latter term (CDE) in their method contains trait changes within species and does not further distinguish between genetic and non-genetic effects. Current partitioning metrics could be used to separate mean species trait change into non-evolutionary and evolutionary components. The resulting partitioning metric is then able to quantify ecological and evolutionary contributions to a shift in ecosystem function characterised as a sum across all species. I anticipate future analyses quantifying the relative contribution of both processes to ecosystem properties that will build from the eco-evolutionary partitioning metrics reviewed here.

The focus on survey data in discrete time periods is valuable because many empirical studies collect information on trait changes across discrete time points, rather than continuous trait change in time (ELLNER et al. 2011). The eco-evolutionary partitioning metrics presented in this study only use information collected on trait values on an initial and a final time point or along an environmental gradient and do not need additional information such as an association between fitness and trait values as is often the case in dynamical models on eco-evolutionary dynamics. Using observed data without making underlying fitness-trait associations implies that these metrics cannot be used in a predictive manner (FRANK 2012; QUELLER 2017) unless additional assumptions about the evolutionary process are taken into account (FRANK 2012; LION 2018). For example, none of the metrics contain information about how alleles are combined or how phenotypic plasticity evolves in subsequent generations (FRANK 2012; QUELLER 2017). The fact that these metrics do not need such additional information make them generally applicable to a diverse array of systems at different levels of abstractness (GARDNER 2008; LUQUE 2017), but limits the capacity to predict future dynamics. In principle, these metrics could be combined with existing dynamical models to determine the expected contribution of ecology and evolution in varying simulated situations. For example, NORBERG et al. (2012) developed a spatially explicit ecoevolutionary model in which population and trait dynamics are followed in response to climate change for a set of species. Specifically, they evaluated how the joint effects of dispersal and genetic variation influenced the relative contributions of ecology and evolution to the community response to a warming climate. To assess the temporal effects of ecology and evolution at each point in space, they used a continuous version of the Price equation. They found that the relative importance of adaptive evolution versus species sorting depended highly on the joint effects of dispersal and genetic variation, but was also determined by the amount of competition present. For example, without competition, species mainly responded to climate change through evolution. The study of NORBERG et al. (2012) is one of the few that combines dynamical modelling with a direct assessment of the importance of evolutionary and ecological processes. More fascinating, the model revealed that the interaction between ecological and evolutionary processes generated species extinctions and trait change long after the climate had stabilised. This reflects the importance of combining different approaches such as dynamical models with partitioning metrics to obtain further insights into which processes may be responsible for the expected trait change.

\section{Outlook}

The field of eco-evolutionary dynamics is still in a relatively early stage (HENDRY 2017). Most studies applied eco-evolutionary partitioning metrics on single populations (e.g., HAIRSTON et al. 2005; EZARD et al. 2009; ElLnER et al. 2011; PANTEL et al. 2015; STOKS et al. 2016; PigÉON et al. 2017), with some exceptions that applied partitioning metrics to predator-prey dynamics (e.g., BECKS et al. 2012; VAN VELZEN \& GAEDKE 2017) or community properties (e.g., COLLINS \& GARDNER 2009; TERHORST et al. 2014; PANTEL et al. 2015). Even in simple two-species systems, eco-evolutionary partitioning metrics can address important questions, such as how does the relative importance of evolution versus ecology change depending on whether a species engages in competition, predation, or mutualism? Generally, the lack of studies applying partitioning metrics to more complex systems such as communities of multiple 
co-occurring species is mainly due at present to the fact that the right data have not been collected. Applying partitioning metrics to more complex systems not only involves a practical challenge (i.e., measuring trait values and abundances of all or most abundant species present), but also a conceptual and quantitative challenge. Can and should complex species interactions be taken into account in partitioning metrics? And would such an approach provide us with better insights into mechanisms of the eco-evolutionary dynamics occurring in the system? Partitioning metrics can be applied to more complex systems as long as the data are collected in such a way that it makes the partition components meaningful. Increasing complexity has, however, the drawback that the method becomes very datahungry. As mentioned earlier, while a reliable and detailed eco-evolutionary partitioning is the goal, simpler approaches may also provide crucial insights into the system under study; as long as the researcher is aware of the limitations and interpretation of this simpler approach.

Most eco-evolutionary studies focus on changes in a single phenotypic trait assuming that it evolves independently of other traits. However, it is well-known that traits can be genetically correlated due to epistasis (i.e., recombination and interactions between loci), pleiotropy (i.e., the same loci influencing multiple traits), or linkage disequilibrium (i.e., non-random association of alleles at different loci) (LEWONTIN \& KOJIMA 1960; LYNCH \& WALSH 1998; SLATKIN 2008) and thus ecological variables may be impacted by multiple traits at the same time (e.g., DEWITT \& LANGERHANS 2003; DERAISON et al. 2015). Attempts to quantify evolutionary and non-evolutionary contributions to multivariate trait change have been made. For example, the study by STOKS et al. (2016) used the reaction norm approach to partition multivariate trait change by including trait vectors as opposed to a single trait value in the reaction norm approach. Including trait vectors into partitioning metrics, however, still does not account for possible correlations between traits. Taking trait correlations into account could be done by performing first a Principal Component Analysis (PCA) on the total data set, and then applying an ecoevolutionary partitioning metric on the principal components. However, while the trait combinations represented by particular principal components are informative about correlations between traits, the interpretation of these results might be more challenging (e.g., if the structure of the PCA changes as traits evolve). Methods to describe multivariate trait change have been extensively developed in fields such as quantitative genetics. These methods could then be combined with eco-evolutionary partitioning metrics to quantify contributions of ecology and evolution to multivariate trait change. For example, the fourth order tensor analysis allows capturing of the variation among a set of covariance matrices, and partitions this variation into independent changes in the covariance structure (HINE et al. 2009). Combining such an approach with common garden data may allow a multivariate way to assess effects of ecology and evolution to a change in the multivariate trait structure.

A major challenge is to understand how eco-evolutionary dynamics play out in natural, non-experimental settings (PELlETIER et al. 2009; HENDRY 2017). However, there are still limited insights about ecoevolutionary dynamics in nature mainly due to restricted knowledge on genotype and phenotype dynamics in wild populations (MERILÄ et al. 2001; KRUUK et al. 2008; BARRACLOUGH 2015), but also because there are few studies that collect field data allowing for meaningful population and community eco-evolutionary partitioning. Such studies should involve monitoring of trait shifts over time in multiple genetic lineages and species through properly designed common garden or transplant experiments. Future community eco-evolutionary studies will ideally track trait evolution of all key species in natural communities and their ecological consequences through time (BARRACLOUGH 2015) and this in spatially complex landscapes. The increase in novel techniques to track abundances and trait values of species (e.g., via species that can be easily recognised, or via genomic techniques or fluorescent labels; BLOUNT et al. 2012; ChUBIZ et al. 2012; HeKSTRA \& LEIBLER 2012; LAWRENCE et al. 2012) will continue to advance the field of eco-evolutionary dynamics. However, currently nearly all studies still track only a limited number of genotypes and the techniques developed to date are only applicable to a subset of organisms (HEKSTRA \& LEIBLER 2012). But, at the current pace of technological innovation it is likely that in the near future it will be possible to simultaneously track trait evolution of multiple species 
and their ecological consequences (BARRACLOUGH 2015). This will enhance theoretical and empirical understanding of how species evolve in a community context, and provide opportunities to study ecoevolutionary dynamics in more complex, natural systems.

Anumber of challenges remain before we will fully understand how important eco-evolutionary processes are for population, community and ecosystem properties. This review has provided an overview of current partitioning metrics available to quantify ecological and evolutionary contributions to population and community trait shifts in a temporal context and addressed how future studies could collect data suited for partitioning metrics at the community level. While there is still only a limited number of studies that directly quantify these contributions, interest in eco-evolutionary dynamics is rapidly growing. I encourage future research to carefully consider how experiments and landscape surveys can provide the data to apply eco-evolutionary partitioning metrics, and expect eco-evolutionary partitioning metrics to further develop and play a central role in the continuing synthesis of ecology and evolution.

\section{Acknowledgments}

I thank Luc De Meester, Jelena H. Pantel, Caroline Souffreau, Giannina Hattich, Nelson Hairston Jr. and two anonymous reviewers for their valuable comments that improved this manuscript. This research was supported by KU Leuven Research Fund excellence financing PF/2010/07, Belspo IUAP project SPEEDY, an IWT PhD fellowship awarded to LG. LG was also supported by the University of Zurich Research Priority Program on 'Global Change and Biodiversity'.

\section{References}

ABRAMS P.A. \& MATSUDA H. (1997). Prey adaptation as a cause of predator- prey cycles. Evolution 51 (6): 1742-1750. https://doi.org/10.2307/2410997

ARNOLD A.J. \& FRISTRUP K. (1982). The theory of evolution by natural selection: a hierarchical expansion. Paleobiology 8 (2): 113-129. https://doi.org/10.1017/S0094837300004462

Arseneau K.M., Driscoll C.T., Brager L.M., Ross K.A. \& Cumming B.F. (2011). Recent evidence of biological recovery from acidification in the Adirondacks (New York, USA): a multiproxy paleolimnological investigation of Big Moose lake. Canadian Journal of Fisheries and Aquatic Sciences 68 (4): 575-592. https://doi.org/10.1139/f2011-003

BARRACLOUGH T.G. (2015). How do species interactions affect evolutionary dynamics across whole communities? Annual Review of Ecology, Evolution, and Systematics 46: 25-48.

https://doi.org/10.1146/annurev-ecolsys-112414-054030

Bassar R.D., Ferriere R., Lopez-Sepulcre A., Marshall M.C., Travis J., Pringle C.M. \& REZNICK D.N. (2012). Direct and indirect ecosystem effects of evolutionary adaptation in the Trinidadian guppy (Poecilia reticulata). The American Naturalist 180 (2): 167-185. https://doi.org/10.1086/666611

Becks L., Ellner S.P., Jones L.E. \& Hairston N.G. (2012). The functional genomics of an ecoevolutionary feedback loop: linking gene expression, trait evolution, and community dynamics. Ecology letters 15 (5): 492-501. https://doi.org/10.1111/j.1461-0248.2012.01763.x

BLOUNT Z.D., BARRICK J.E., DAVIDSON C.J. \& LENSKI R.E. (2012). Genomic analysis of a key innovation in an experimental Escherichia coli population. Nature 489 (7417): 513-518. https://doi.org/10.1038/nature11514

Brans K.I., Govaert L., Engelen J.M., Gianuca A.T., Souffreau C. \& De Meester L. (2017). Eco-evolutionary dynamics in urbanized landscapes: evolution, species sorting and the change in zoo- 
plankton body size along urbanization gradients. Philosophical Transactions of the Royal Society B 372 (1712): 20160030. https://doi.org/10.1098/rstb.2016.0030

Charmantier A., McCleery R.H., Cole L.R., Perrins C., Kruuk L.E. \& Sheldon B.C. (2008). Adaptive phenotypic plasticity in response to climate change in a wild bird population. Science 320 (5877): 800-803. https://doi.org/10.1126/science.1157174

Chubiz L.M., Lee M.-C., Delaney N.F. \& MarX C.J. (2012). Freq-seq: a rapid, cost-effective, sequencing-based method to determine allele frequencies directly from mixed populations. PLoS One 7 (10): e47959. https://doi.org/10.1371/journal.pone.0047959

Clutton-Brock T.H. \& Pemberton J.M. (2004). Soay Sheep: Dynamics and Selection in an Island Population. Cambridge University Press.

COLLINS S. \& GARDNER A. (2009). Integrating physiological, ecological and evolutionary change: a Price equation approach. Ecology Letters 12 (8): 744-757. https://doi.org/10.1111/j.1461-0248.2009.01340.x

CoOK-Patton S.C., McArt S.H., Parachnowitsch A.L., Thaler J.S. \& Agrawal A.A. (2011). A direct comparison of the consequences of plant genotypic and species diversity on communities and ecosystem function. Ecology 92 (4): 915-923. https://doi.org/10.1890/10-0999.1

COULSON T. (2012). Integral projections models, their construction and use in posing hypotheses in ecology. Oikos 121 (9): 1337-1350. https://doi.org/10.1111/j.1600-0706.2012.00035.x

COULSON T. \& TUlJAPURKAR S. (2008). The dynamics of a quantitative trait in an agestructured population living in a variable environment. The American Naturalist 172 (5): 599. https://doi.org/10.1086/591693

COUlson T., TUlJapurkar S. \& ChildS D.Z. (2010). Using evolutionary demography to link life history theory, quantitative genetics and population ecology. Journal of Animal Ecology 79 (6): 12261240. https://doi.org/10.1111/j.1365-2656.2010.01734.x

Coulson T., MacNulty D.R., Stahler D.R., von Holdt B., Wayne R.K. \& Smith D.W. (2011). Modeling effects of environmental change on wolf population dynamics, trait evolution and life history. Science 334 (6060): 1275-1278. https://doi.org/10.1126/science.1209441

DAY T. (2005). Modelling the ecological context of evolutionary change: déjà vue or something new? Ecological Paradigms lost: Routes of Theory Change 2, Chapter 13: 273-310.

https://doi.org/10.1016/B978-012088459-9/50015-7

DAY T. \& GANDON S. (2006). Insights from Price's equation into evolutionary. Disease Evolution: Models, Concepts, and Data Analyses 71: 23-44.

Day T., Pritchard J. \& Schluter D. (1994). A comparison of two sticklebacks. Evolution 48 (5) : 1723-1734. https://doi.org/10.1111/j.1558-5646.1994.tb02208.x

De Meester L., Louette G., Duvivier C., Van Damme C. \& Michels E. (2007). Genetic composition of resident populations influences establishment success of immigrant species. Oecologia 153 (2): 431440. https://doi.org/10.1007/S00442-007-0721-3

Deraison H., BADENhausser I., BÖRgER L. \& Gross N. (2015). Herbivore effect traits and their impact on plant community biomass: an experimental test using grasshoppers. Functional Ecology 29, 5, 650-661. https://doi.org/10.1111/1365-2435.12362

Des Roches S., Post D.M., Turley N.E., Bailey J.K., Hendry A.P., Kinnison M.T., SchweitZer J.A. \& PALKOVACS E.P. (2018). The ecological importance of intraspecific variation. Nature Ecology \& Evolution 2 (1): 57. https://doi.org/10.1038/s41559-017-0402-5 
DeWitT T.J. \& Langerhans R.B. (2003). Multiple prey traits, multiple predators: keys to understanding complex community dynamics. Journal of Sea Research 49 (2): 143-155. https://doi.org/10.1016/S1385-1101(02)00220-4

DeWitT T.J., SiH A. \& WiLSON D.S. (1998). Costs and limits of phenotypic plasticity. Trends in Ecology \& Evolution 13 (2): 77-81. https://doi.org/10.1016/S0169-5347(97)01274-3

Dinh VAn K., Janssens L., Debecker S. \& Stoks R. (2014). Temperature-and latitude-specific individual growth rates shape the vulnerability of damselfly larvae to a widespread pesticide. Journal of Applied Ecology 51 (4): 919-928. https://doi.org/10.1111/1365-2664.12269

EASTERling M.R., Ellner S.P. \& DiXON P.M. (2000). Size-specific sensitivity: applying a new structured population model. Ecology 81 (3): 694-708.

https://doi.org/10.1890/0012-9658(2000)081[0694:SSSAAN]2.0.CO;2

ELENA S. \& LENSKI R. (2003). Microbial genetics: Evolution experiments with microorganisms: the dynamics and genetic bases of adaptation. Nature Reviews Genetics 4: 457-469.

https://doi.org/10.1038/nrg1088

Ellner S.P., Geber M.A. \& HAirston N.G. (2011). Does rapid evolution matter? Measuring the rate of contemporary evolution and its impacts on ecological dynamics. Ecology Letters 14 (6): 603-614. https://doi.org/10.1111/j.1461-0248.2011.01616.x

ETtERSON, J. R. \& SHAW R. G. (2001). Constraint to adaptive evolution in response to global warming. Science 294, 5540, 151-154. https://doi.org/10.1126/science.1063656

Ezard T.H.G., Steeve D.C. \& Pelletier F. (2009). Eco-evolutionary dynamics: disentangling phenotypic, environmental and population fluctuations. Philosophical Transactions of the Royal Society of London B: Biological Sciences 364 (1523): 1491-1498. https://doi.org/10.1098/rstb.2009.0006

Farkas T.E., Mononen T., Comeault A.A., Hanski I. \& Nosil P. (2013). Evolution of camouflage drives rapid ecological change in an insect community. Current Biology 23 (19): 1835-1843. https://doi.org/10.1016/j.cub.2013.07.067

Fiegna F., Scheuerl T., Moreno-Letelier A., Bell T. \& Barraclough T.G. (2015). Saturating effects of species diversity on life-history evolution in bacteria. Proceedings of the Royal Society B: Biological Sciences 282: 20151794. https://doi.org/10.1098/rspb.2015.1794

FISHER R. (1930). Genetics, mathematics, and natural selection. Nature 126: 805-806. https://doi.org/10.1038/126805a0

FISHER R.A. (1941). Average excess and average effect of a gene substitution. Annals of Human Genetics 11 (1): 53-63. https://doi.org/10.1111/j.1469-1809.1941.tb02272.x

FOX J.W. (2006). Using the Price equation to partition the effects of biodiversity loss on ecosystem function. Ecology 87 (11): 2687-2696.

https://doi.org/10.1890/0012-9658(2006)87[2687:UTPETP]2.0.CO;2

FOX J.W. \& HARDER L.D. (2015). Using a "time machine" to test for local adaptation of aquatic microbes to temporal and spatial environmental variation. Evolution 69 (1): 136-145.

https://doi.org/10.1111/evo.12543

FOX J.W. \& HARPOLE W.S. (2008). Revealing how species loss affects ecosystem function: the traitbased Price equation partition. Ecology 89 (1): 269-279. https://doi.org/10.1890/07-0288.1

FOX J.W. \& KERR B. (2012). Analyzing the effects of species gain and loss on ecosystem function using the extended Price equation partition. Oikos 121 (2): 290-298.

https://doi.org/10.1111/j.1600-0706.2011.19656.x 
FRANK S.A. (2012). Natural selection. IV. the Price equation. Journal of Evolutionary Biology 25 (6): 1002-1019. https://doi.org/10.1111/j.1420-9101.2012.02498.x

Fronhofer E., Gut S. \& Altermatt F. (2017). Evolution of density- dependent movement during experimental range expansions. Journal of Evolutionary Biology 30 (12): 2165-2176. https://doi.org/10.1111/jeb.13182

Fukami T., Beaumont H.J., Zhang X.-X. \& RAINEY P.B. (2007). Immigration history controls diversification in experimental adaptive radiation. Nature 446, 7134, 436-439. https://doi.org/10.1038/nature05629

FusSMANN G., LOREAU M. \& ABRAMS P. (2007). Eco-evolutionary dynamics of communities and ecosystems. Functional Ecology 21 (3): 465-477.

Gasol J.M., Comerma M., García J.C., Armengol J., Casamayor E.O., KoJecká P. \& Šimek K. (2002). A transplant experiment to identify the factors controlling bacterial abundance, activity, production, and community composition in a eutrophic canyon-shaped reservoir. Limnology and Oceanography 47 (1): 62-77. https://doi.org/10.4319/1o.2002.47.1.0062

Genung M.A., Schweitzer J.A., Ubeda F., FitzPatrick B.M., Pregitzer C.C., FelKer-Quinn E. \& BAILEY J.K. (2011). Genetic variation and community change-selection, evolution, and feedbacks. Functional Ecology 25 (2): 408-419. https://doi.org/10.1111/j.1365-2435.2010.01797.x

Govaert L., PANTEL J.H. \& DE MeEster L. (2016). Eco-evolutionary partitioning metrics: assessing the importance of ecological and evolutionary contributions to population and community change. Ecology Letters 19 (8): 839-853. https://doi.org/10.1111/ele.12632

Grafen A. (2000). Developments of the Price equation and natural selection under uncertainty. Proceedings of the Royal Society of London B: Biological Sciences 267 (1449): 1223-1227. https://doi.org/10.1098/rspb.2000.1131

GrAfEn A. (2015). Biological fitness and the Price equation in class-structured populations. Journal of Theoretical Biology 373: 62-72. https://doi.org/10.1016/j.jtbi.2015.02.014

GRANT P.R. \& GRANT B.R. (2002). Unpredictable evolution in a 30-year study of Darwin's finches. science 296 (5568): 707-711. https://doi.org/10.1126/science.1070315

Gravel D., Bell T., Barbera C., Bouvier T., Pommier T., Venail P. \& Mouquet N. (2011). Experimental niche evolution alters the strength of the diversity-productivity relationship. Nature 469 (7328): 89-92. https://doi.org/10.1038/nature09592

Hairston N.G., Ellner S.P., Geber M.A., Yoshida T. \& Fox J.A. (2005). Rapid evolution and the convergence of ecological and evolutionary time. Ecology Letters 8 (10): 1114-1127.

https://doi.org/10.1111/j.1461-0248.2005.00812.x

HAMILTON W.D. (1975). Innate social aptitudes of man: an approach from evolutionary genetics. Biosocial Anthropology 133: 115-132.

HARDEN J.W. (1982). A quantitative index of soil development from field descriptions: Examples from a chronosequence in central California. Geoderma 28 (1): 1-28.

https://doi.org/10.1016/0016-7061(82)90037-4

Harmon L.J., Matthews B., Des Roches S., Chase J.M., Shurin J.B. \& Schluter D. (2009). Evolutionary diversification in stickleback affects ecosystem functioning. Nature 458 (7242): 11671170. https://doi.org/10.1038/nature07974

HeKstRA D.R. \& LeIBLER S. (2012). Contingency and statistical laws in replicate microbial closed ecosystems. Cell 149 (5): 1164-1173. https://doi.org/10.1016/j.cell.2012.03.040 
HENDERSON C.R. (1950). Estimation of genetic parameters. The Annals of Mathematical Statistics 21: 309-310.

HENDRY A. (2013). Key questions in the genetics and genomics of eco-evolutionary dynamics. Heredity 111 (6): 456-466. https://doi.org/10.1038/hdy.2013.75

HENDRY A.P. (2017). Eco-Evolutionary Dynamics. Princeton University Press.

Hine E., Chenoweth S.F., Rundle H.D. \& Blows M.W. (2009). Characterizing the evolution of genetic variance using genetic covariance tensors. Philosophical Transactions of the Royal Society of London B: Biological Sciences 364(1523): 1567-1578. https://doi.org//10.1098/rstb.2008.0313

JOHNSON M.T. \& STINCHCOMBE J.R. (2007). An emerging synthesis between community ecology and evolutionary biology. Trends in Ecology \& Evolution 22 (5): 250-257. https://doi.org/10.1016/j.tree.2007.01.014

Jones A.G., Small C.M., Paczolt K.A. \& Ratterman N.L. (2010). A practical guide to methods of parentage analysis. Molecular Ecology Resources 10 (1): 6-30.

https://doi.org/10.1111/j.1755-0998.2009.02778.x

KAWECKI T.J. \& EBERT D. (2004). Conceptual issues in local adaptation. Ecology Letters 7 (12): 1225 1241. https://doi.org/10.1111/j.1461-0248.2004.00684.x

KERFOOT W.C. \& WEIDER L.J. (2004). Experimental paleoecology (resurrection ecology): chasing Van Valen's Red Queen hypothesis. Limnology and Oceanography 49 (4, part 2): 1300-1316.

https://doi.org/10.4319/1o.2004.49.4_part_2.1300

KERFOOT W.C., RobBIns J.A. \& WeIDER L.J. (1999). A new approach to historical recon-struction: combining descriptive and experimental paleolimnology. Limnology and Oceanography 44 (5): 12321247. https://doi.org/10.4319/lo.1999.44.5.1232

KerR B. \& GODFrey-Smith P. (2009). Generalization of the Price equation for evolutionary change. Evolution: International Journal of Organic Evolution 63 (2): 531-536.

https://doi.org/10.1111/j.1558-5646.2008.00570.x

KruUk L.E., Slate J. \& Wilson A.J. (2008). New answers for old questions: the evolutionary quantitative genetics of wild animal populations. Annual Review of Ecology, Evolution, and Systematics 39. https://doi.org/10.1146/annurev.ecolsys.39.110707.173542

LAJOIE G. \& Vellend M. (2015). Understanding context dependence in the contribution of intraspecific variation to community trait-environment matching. Ecology 96 (11): 2912-2922. https://doi.org/10.1890/15-0156.1

LANDE R. \& ARNOLD S.J. (1983). The measurement of selection on correlated characters. Evolution 37 (6): 1210-1226. https://doi.org/10.1111/j.1558-5646.1983.tb00236.x

Lawrence D., Fiegna F., Behrends V., Bundy J.G., Phillimore B., Bell T. \& Barraclough T.G. (2012). Species interactions alter evolutionary responses to a novel environment. PLoS Biol 10 (5): e1001330. https://doi.org/10.1371/journal.pbio.1001330

LENNON J.T. \& MARTINY J.B. (2008). Rapid evolution buffers ecosystem impacts of viruses in a microbial food web. Ecology Letters 11 (11): 1178-1188.

https://doi.org/10.1111/j.1461-0248.2008.01225.x

LENSKI R.E., ROSE M.R., SIMPSON S.C. \& TADLER S.C. (1991). Long- term experimental evolution in Escherichia coli. I. adaptation and divergence during 2,000 generations. The American Naturalist 138 (6): 1315-1341. https://doi.org/10.1086/285289 
LePŠ J., DE Bello F., ŠMilauer P. \& DoležAl J. (2011). Community trait response to environment: disentangling species turnover vs intraspecific trait variability effects. Ecography 34 (5): 856-863. https://doi.org/10.1111/j.1600-0587.2010.06904.x

LEVIN S.A. (1972). A mathematical analysis of the genetic feedback mechanism. The American Naturalist 106 (948): 145-164. https://doi.org/10.1086/282758

LEWONTIN R. \& KOJIMA K.-I. (1960). The evolutionary dynamics of complex polymorphisms. Evolution 14 (4): 458-472. https://doi.org/10.1111/j.1558-5646.1960.tb03113.x

LION S. (2018). From the Price equation to the selection gradient in class-structured populations: a quasi-equilibrium route. Journal of theoretical biology 447C: 21-44.

https://doi.org/10.1016/j.jtbi.2018.03.033

LOEUILLE N. (2010). Influence of evolution on the stability of ecological communities. Ecology Letters 13 (12): 1536-1545. https://doi.org/10.1111/j.1461-0248.2010.01545.x

LOEUILLE N. \& LEIBOLD M.A. (2008). Evolution in metacommunities: on the relative importance of species sorting and monopolization in structuring communities. The American Naturalist 171 (6): 788 799. https://doi.org/10.1086/587745

LUQUE V.J. (2017). One equation to rule them all: a philosophical analysis of the Price equation. Biology \& Philosophy 32 (1): 97-125. https://doi.org/10.1007/s10539-016-9538-y

Lush J.L. (1947). Animal Breeding Plans. The Iowa State College Press.

LyNCH M. \& WALSH B. (1998). Genetics and Analysis of Quantitative Traits. Vol. 1. Sinauer Sunderland, MA.

MADRITCH M.D. \& LINDROTH R.L. (2011). Soil microbial communities adapt to genetic variation in leaf litter inputs. Oikos 120 (11): 1696-1704. https://doi.org/10.1111/j.1600-0706.2011.19195.x

Matthews B., Narwani A., Hausch S., Nonaka E., Peter H., Yamamichi M., Sullam K.E., Bird K.C., Thomas M.K., HANLEY T.C. \& TURNER C.B. (2011). Toward an integration of evolutionary biology and ecosystem science. Ecology Letters 14 (7): 690-701.

https://doi.org/10.1111/j.1461-0248.2011.01627.x

MERILÄ J. \& HENDRY A.P. (2014). Climate change, adaptation, and phenotypic plasticity: the problem and the evidence. Evolutionary applications 7 (1): 1-14. https://doi.org/10.1111/eva.12137

MERILÄ J., SHELdON B. \& KRUUK L. (2001). Explaining stasis: microevolutionary studies in natural populations. Genetica 112 (1): 199-222. https://doi.org/10.1023/A:1013391806317

Metcalf C.J.E., Rose K.E., Childs D.Z., Sheppard A.W., Grubb P.J. \& Rees M. (2008). Evolution of flowering decisions in a stochastic, density-dependent environment. Proceedings of the National Academy of Sciences 105 (30): 10466-10470. https://doi.org//10.1073/pnas.0800777105

NEWMAN R.A. (1994). Genetic variation for phenotypic plasticity in the larval life history of spadefoot toads (Scaphiopus couchii). Evolution 48 (6): 1773-1785.

https://doi.org/10.1111/j.1558-5646.1994.tb02213.x

NoOten S.S., ANDREW N.R. \& Hughes L. (2014). Potential impacts of climate change on insect communities: a transplant experiment. PLoS One 9 (1): e85987.

https://doi.org/10.1371/journal.pone.0085987

Norberg J., Urban M.C., Vellend M., Klausmeier C.A. \& Loeuille N. (2012). Ecoevolutionary responses of biodiversity to climate change. Nature Climate Change 2 (10): 747-751. https://doi.org/10.1038/nclimate1588 
Nussey D.H., Clutton-Brock T.H., Elston D.A., Albon S.D. \& KruUK L.E. (2005a). Phenotypic plasticity in a maternal trait in red deer. Journal of Animal Ecology 74 (2): 387-396. https://doi.org/10.1111/j.1365-2656.2005.00941.x

Nussey D.H., Postma E., GienAPP P. \& VisSER M.E. (2005b). Selection on heritable phenotypic plasticity in a wild bird population. Science 310 (5746): 304-306. https://doi.org/10.1126/science.1117004

Ozgul A., Tuljapurkar S., Benton T.G., Pemberton J.M., Clutton-Brock T.H. \& Coulson T. (2009). The dynamics of phenotypic change and the shrinking sheep of St. Kilda. Science 325 (5939): 464-467. https://doi.org/10.1126/science.1173668

Ozgul A., Childs D.Z., Oli M.K., Armitage K.B., Blumstein D.T., Olson L.E., Tuljapurkar S. \& COULSON T. (2010). Coupled dynamics of body mass and population growth in response to environmental change. Nature 466 (7305): 482. https://doi.org/10.1038/nature09210

PAGE K.M. \& NOWAK M.A. (2002). Unifying evolutionary dynamics. Journal of theoretical biology 219 (1): 93-98. https://doi.org/10.1006/jtbi.2002.3112

Pantel J.H., Leibold M.A. \& Juenger T.E. (2011). Population differentiation in Daphnia alters community assembly in experimental ponds. The American Naturalist 177 (3): 314-322. https://doi.org/10.1086/658345

Pantel J.H., Duvivier C. \& De Meester L. (2015). Rapid local adaptation mediates zooplankton community assembly in experimental mesocosms. Ecology Letters 18 (10): 992-1000. https://doi.org/10.1111/ele.12480

Pelletier F., GARANT D. \& Hendry A. (2009). Eco-evolutionary dynamics. Philosophical Transactions of the Royal Society B: Biological Sciences 364: 1483-1489.

https://doi.org/10.1098/rstb.2009.0027

PICKETT S.T. (1989). Space-for-time substitution as an alternative to long-term studies. In: LiKENS G.E. (ed.) Long-Term Studies in Ecology: 110-135. Springer.

https://doi.org/10.1007/978-1-4615-7358-6_5

Pigéon G., Ezard T.H., Festa-Bianchet M., Coltman D.W. \& Pelletier F. (2017). Fluctuating effects of genetic and plastic changes in body mass on population dynamics in a large herbivore. Ecology 98 (9): 1-40. https://doi.org/10.1002/ecy.1940

PigliucCi M. (2001). Phenotypic Plasticity: beyond Nature and Nurture. JHU Press.

PIMENTEL D. (1961). Animal population regulation by the genetic feed-back mechanism. The American Naturalist 95 (881): 65-79. https://doi.org/10.1086/282160

PIMENTEL D. (1968). Population regulation and genetic feedback. Science 159 (3822): 1432-1437. https://doi.org/10.1126/science.159.3822.1432

Post D.M. \& PALKovacs E.P. (2009). Eco-evolutionary feedbacks in community and ecosystem ecology: interactions between the ecological theatre and the evolutionary play. Philosophical Transactions of the Royal Society B: Biological Sciences 364 (1523): 1629-1640. https://doi.org/10.1098/rstb.2009.0012

PRICE G.R. (1970). Selection and covariance. Nature 227: 520-21. https://doi.org/10.1038/227520a0

PRICE G.R. (1972). Extension of covariance selection mathematics. Annals of Human Genetics 35 (4): 485-490. https://doi.org/10.1111/j.1469-1809.1957.tb01874.x

QUELLER D.C. (2017). Fundamental theorems of evolution. The American Naturalist 189 (4): 345-353. https://doi.org/10.1086/690937 
Réale D., McAdam A.G., Boutin S. \& Berteaux D. (2003). Genetic and plastic responses of a northern mammal to climate change. Proceedings of the Royal Society of London B: Biological Sciences 270 (1515): 591-596. https://doi.org/10.1098/rspb.2002.2224

Reinemann S.A., Porinchu D.F., Bloom A.M., Mark B.G. \& Box J.E. (2009). A multi-proxy paleolimnological reconstruction of holocene climate conditions in the Great Basin, United States. Quaternary Research 72 (3): 347-358. https://doi.org/10.1016/j.yqres.2009.06.003

REZNICK D.N. (2013). A critical look at reciprocity in ecology and evolution: introduction to the symposium. The American Naturalist 181: S1-S8. https://doi.org/10.1086/670030

RICE S.H. (2008). A stochastic version of the Price equation reveals the interplay of deterministic and stochastic processes in evolution. BMC Evolutionary Biology 8 (1): 262-278. https://doi.org/10.1186/1471-2148-8-262

Rice S.H. \& PAPAdOPOUlos A. (2009). Evolution with stochastic fitness and stochastic migration. PloS One 4 (10): e7130. https://doi.org/10.1371/journal.pone.0007130

ROBERTSON A. (1966). A mathematical model of the culling process in dairy cattle. Animal Science 8 (1): 95-108. https://doi.org/10.1017/S0003356100037752

RoBerTSON A. (1968). The spectrum of genetic variation. In: LEWONTIN R.C. (ed.), Population Biology and Evolution: 5-16.

RofF D.A. (2007). A centennial celebration for quantitative genetics. Evolution: International Journal of Organic Evolution 61 (5): 1017-1032. https://doi.org/10.1111/j.1558-5646.2007.00100.x

SCHOENER T.W. (2011). The newest synthesis: understanding the interplay of evolutionary and ecological dynamics. Science 331 (6016): 426-429. https://doi.org/10.1126/science.1193954

SchWeitzer J.A., BAiley J.K., HART S.C. \& Whitham T.G. (2005). Nonadditive effects of mixing cottonwood genotypes on litter decomposition and nutrient dynamics. Ecology 86 (10): 2834-2840. https://doi.org/10.1890/04-1955

SHEFFERSON R.P. \& SALGUERO-GÓMEZ R. (2015). Eco-evolutionary dynamics in plants: interactive processes at overlapping time-scales and their implications. Journal of Ecology 103 (4): 789-797. https://doi.org/10.1111/1365-2745.12432

SLATKIN M. (2008). Linkage disequilibrium understanding the evolutionary past and mapping the medical future. Nature Reviews Genetics 9 (6): 477-485. https://doi.org/10.1038/nrg2361

SMALLEGANGE I.M. \& COULSON T. (2013). Towards a general, population- level understanding of ecoevolutionary change. Trends in Ecology \& Evolution 28 (3): 143-148.

https://doi.org/10.1016/j.tree.2012.07.021

SpaAK J.W., BAert J.M., BAird D.J., EISEnhauer N., MAltby L., Pomati F., RAdChUK V., Rohr J.R., VAN DEN BRINK P.J. \& DE LAENDER F. (2017). Shifts of community composition and population density substantially affect ecosystem function despite invariant richness. Ecology Letters 20 (10): 1315-1324. https://doi.org/10.1111/ele.12828

SteVens P. \& WALKeR T. (1970). The chronosequence concept and soil formation. The Quarterly Review of Biology 45 (4): 333-350. https://doi.org/10.1086/406646

Stoks R., Govaert L., Pauwels K., Jansen B. \& De Meester L. (2016). Resurrecting complexity: the interplay of plasticity and rapid evolution in the multiple trait response to strong changes in predation pressure in the water flea Daphnia magna. Ecology Letters 19 (2): 180-190.

https://doi.org/10.1111/ele.12551 
SyMSTAD A.J., TILMAN D., Willson J. \& KNOPS J.M. (1998). Species loss and ecosystem functioning: effects of species identity and community composition. Oikos 81 (2): 389-397. https://doi.org/10.2307/3547058

TERHORST C.P., LENNON J.T. \& LAU J.A. (2014). The relative importance of rapid evolution for plantmicrobe interactions depends on ecological context. Proceedings of the Royal Society of London B: Biological Sciences 281 (1785): 20140028. https://doi.org/10.1098/rspb.2014.0028

Traill L.W., Schindler S. \& Coulson T. (2014). Demography, not inheritance, drives phenotypic change in hunted bighorn sheep. Proceedings of the National Academy of Sciences 111 (36): 1322313228. https://doi.org/10.1073/pnas.1407508111

TURCOTte M.M., ReZniCK D.N. \& HARE J.D. (2011). The impact of rapid evolution on population dynamics in the wild: experimental test of eco-evolutionary dynamics. Ecology Letters 14 (11): 10841092. https://doi.org/10.1111/j.1461-0248.2011.01676.x

URBAN M.C. (2013) Evolution mediates the effects of apex predation on aquatic food webs. Proceedings of the Royal Society B: Biological Sciences 280: 20130859. https://doi.org/10.1098/rspb.2013.0859

URBAN M.C. \& DE MEESTER L. (2009). Community monopolization: local adaptation enhances priority effects in an evolving metacommunity. Proceedings of the Royal Society of London B: Biological Sciences 276 (1676): 4129-4138. https://doi.org/10.1098/rspb.2009.1382

Urban M.C., Leibold M.A., Amarasekare P., De Meester L., GomulKiewicz R., Hochberg M.E., Klausmeier C.A., Loeuille N., De Mazancourt C., Norberg J., Pantel J.H., Strauss S.Y., VELLEND M. \& WADE M.J. (2008). The evolutionary ecology of metacommunities. Trends in Ecology \& Evolution 23 (6): 311-317. https://doi.org/10.1016/j.tree.2008.02.007

van Benthem K.J., Bruijning M., Bonnet T., Jongejans E., Postma E. \& Ozgul A. (2017). Disentangling evolutionary, plastic and demographic processes underlying trait dynamics: a review of four frameworks. Methods in Ecology and Evolution 8 (1): 75-85.

https://doi.org/10.1111/2041-210X.12627

Van Doorslaer W., Stoks R., Jeppesen E. \& De Meester L. (2007). Adaptive microevolutionary responses to simulated global warming in Simocephalus vetulus: a mesocosm study. Global Change Biology 13 (4): 878-886. https://doi.org/10.1111/j.1365-2486.2007.01317.x

VAN Velzen E. \& GAEDKe U. (2017). Disentangling eco-evolutionary dynamics of predator-prey coevolution: the case of antiphase cycles. Scientific Reports 7 (1): 17125.

https://doi.org/10.1038/s41598-017-17019-4

VIA S. \& HAWTHORNE D. (2005). Back to the future: genetic correlations, adaptation and speciation. Genetics of Adaptation 123 (1-2): 147-156. https://doi.org/10.1007/s10709-004-2731-y

VIA S. \& LANDE R. (1985). Genotype-environment interaction and the evolution of phenotypic plasticity. Evolution 39 (3): 505-522. https://doi.org/10.1111/j.1558-5646.1985.tb00391.x

Via S., Gomulkiewicz R., De Jong G., Scheiner S.M., Schlichting C.D. \& VAn Tienderen P.H. (1995). Adaptive phenotypic plasticity: consensus and controversy. Trends in Ecology \& Evolution 10 (5): 212-217. https://doi.org/10.1016/S0169-5347(00)89061-8

WagG C., Bender S.F., Widmer F. \& VAn Der Heijden M.G. (2014). Soil biodiversity and soil community composition determine ecosystem multifunctionality. Proceedings of the National Academy of Sciences 111 (14): 5266-5270. https://doi.org/10.1073/pnas.1320054111

WALKer L.R., WARDLE D.A., BARDgetT R.D. \& Clarkson B.D. (2010). The use of chronosequences in studies of ecological succession and soil development. Journal of Ecology 98 (4): 725-736. https://doi.org/10.1111/j.1365-2745.2010.01664.x 
WeIDER L.J., JeYASINGH P.D. \& LOOPER K.G. (2008). Stoichiometric differences in food quality: impacts on genetic diversity and the coexistence of aquatic herbivores in a Daphnia hybrid complex. Oecologia 158 (1): 47-55. https://doi.org/10.1007/s00442-008-1126-7

Williams J.L., Auge H. \& MARON J.L. (2008). Different gardens, different results: native and introduced populations exhibit contrasting phenotypes across common gardens. Oecologia 157 (2): 239-248. https://doi.org/10.1007/s00442-008-1075-1

Wilson A.J., Reale D., Clements M.N., Morrissey M.M., Postma E., Walling C.A., KRUUK L.E.B. \& NUSSEY D.H. (2010). An ecologist's guide to the animal model. Journal of Animal Ecology 79 (1): 13-26. https://doi.org//10.1111/j.1365-2656.2009.01639.x

Yoshida T., Jones L.E., Ellner S.P., Fussmann G.F. \& Hairston N.G. (2003). Rapid evolution drives ecological dynamics in a predator-prey system. Nature 424 (6946): 303-306. https://doi.org/10.1038/nature01767

Yoshida T., Ellner S.P., Jones L.E., Bohannan B.J., LENSKi R.E. \& HAIRSTON JR N.G. (2007). Cryptic population dynamics: rapid evolution masks trophic interactions. PLoS Biology 5 (9): e235. https://doi.org/10.1371/journal.pbio.0050235

ZHENG X.-X., LiU, G.-H., FU, B.-J., JiN T.-T. \& LIU Z.-F. (2010). Effects of biodiversity and plant community composition on productivity in semiarid grasslands of Hulunbeir, Inner Mongolia, China. Annals of the New York Academy of Sciences 1195 (1): E52-E64. https://doi.org/10.1111/j.1749-6632.2009.05405.x

Manuscript received: 18 May 2018

Manuscript accepted: 7 November 2018

Published on: 11 December 2018

Branch editor: Ellen Decaestecker 